\title{
O agente antrópico como formador de ambientes: química, física e classificação de antropossolos
}

\section{Anthropogenic agents as formers of environments: chemistry, physics and classification of anthroposols}

\author{
Marcelo Batista Krause, Universidade Federal de Viçosa, Brasil, marcelokrausegeo@gmail.com \\ (D) https://orcid.org/0000-0003-4083-4838 \\ André Luiz Lopes de Faria, Universidade Federal de Viçosa, Brasil, andre@ufv.br \\ (iD) https://orcid.org/0000-0003-0492-9725 \\ Rafael Cardoso Teixeira, Secretaria de Estado de Educação de Minas Gerais, Brasil, \\ teixeirarcgeo@gmail.com \\ Dttps://orcid.org/0000-0003-4890-8707 \\ Liovando Marciano da Costa, Universidade Federal de Viçosa, Brasil, liovandomc2021@gmail.com \\ (D) https://orcid.org/0000-0001-9581-0783
}

\begin{abstract}
Resumo: $O$ desenvolvimento da sociedade tecnicista tem gerado impactos sobre o globo terrestre. A ação humana ainda é extremamente discutida como fator de formação dos solos e como agente geológico. O Antropoceno/Tecnógeno é o período no qual o ser humano tornou-se um agente geológico. Com a capacidade de transformar ambientes, recuperando ou poluindo, o agente antrópico é fundamental para compreender as paisagens atuais em todo o globo. A formação dos Antropossolos seria o resultado desse impacto, direto ou indireto, sobre o meio natural. $\mathrm{O}$ objetivo deste artigo é classificar perfis de Antropossolos, localizados na Serra de Santa Maria, município de Visconde do Rio Branco, estado de Minas Gerais - Brasil. A caracterização e a classificação dessa nova ordem visam compreender as características físicas, químicas, mineralógicas e de uso e ocupação das terras. A associação de metodologias para interpretação e descrição permitiu relacionar a gênese e a descrição morfológica de cada perfil. A distribuição espacial dos elementos químicos contribuiu para entender como os Antropossolos se formaram e como estão se adaptando e evoluindo com o ambiente ao qual estão inseridos.
\end{abstract}

Palavras-chave: Alterações; Antropoceno; Técnica.

Abstract: The development of technical society has generated impacts on the globe. Human action is still highly discussed as a soil formation factor and as a geological agent. The Anthropocene/Technogene is the period to which the human has become a geological agent. With the ability to transform environments, recovering or polluting, the anthropic agent is critical to understand current landscapes around the world. The formation of anthroposols would be the result of this impact direct or indirect on the natural environment. The purpose of this article is to classify Anthroposols profiles located in Santa Maria Mountain range, city of the Visconde do Rio Branco, state of Minas Gerais - Brazil. The characterization and classification of this new order aimed to understand the physical, chemical, mineralogical and land use and occupation. The association of methodologies for interpretation and description allowed relating the genesis and morphological description of each profile. The spatial distribution of chemical elements contributed to understanding how Anthroposols have formed and how they are adapting and evolving with the environment to which they are inserted.

Keywords: Changes; Anthropocene; Technics. 


\section{Introdução}

A paisagem é uma herança dos processos fisiográficos, biológicos e principalmente, do patrimônio coletivo dos povos (Ab'Saber, 2003). Sua composição mostra como a forma de vida humana prosperou e se organizou, de acordo, com o ambiente natural. A importância de estudar a fisiografia paisagística e como a sociedade interage com ela é fundamental para explicar a evolução geológica e histórico-social, principalmente em escalas locais, já que, com o fim da última glaciação, há cerca de 10.000 anos, as mudanças ambientais permitiram o avanço dos seres humanos pela superfície terrestre (Oliveira et al., 2005).

Diante das possibilidades de alterar direta e indiretamente o ambiente natural, com objetivos de beneficiar a sua organização socialmente hierarquizada, o ser humano se tornou um agente formador e transformador de paisagens, podendo citar como exemplo: atividades minerárias, aterramentos, canalizações e planificações para instalação de moradias e vias de circulação (Tarolli e Sofia, 2016).

$\mathrm{O}$ uso e ocupação das terras tem alterado sistematicamente as diversas paisagens do planeta. Alguns desses usos têm gerado diferentes depósitos e solos antropogênicos, tal como os Antropossolos, relacionados com a produção de resíduos sólidos, líquidos, domésticos ou industriais, restos de construção civil, áreas de empréstimos e aterros (Curcio et al., 2004).

Portanto, o Antropoceno é um período revolucionário no qual o ser humano se torna um agente geológico fundamental na formação de processos e formas superficiais, deixando de ser um mero modificador (Peloggia e Oliveira, 2005) e a antropogênese se caracteriza por ações humanas sobre o ambiente (Curcio et al., 2004).

A modificação da paisagem pela sociedade altera a capacidade de resiliência, os fluxos de matéria e energia, potencializando a contaminação de aquíferos e a suscetibilidade à erosão. A produção, incorporação e o descarte desses materiais com características distintas nos solos naturais tornam a classe dos solos antrópicos a maior em expansão de ocorrência (Curcio et al., 2004).

Contudo, é relevante destacar que, se comparado ao tempo geológico, o período de existência do ser humano sobre a Terra é insignificante, mas tem relação direta com os processos contemporâneos, devido à intensidade ao qual os processos ocorrem, muitas vezes, superando os equivalentes naturais (Oliveira et al., 2005).

Diante disso, os Antropossolos são as formações compreendidas no período Antropoceno, como consequência das alterações na paisagem das últimas décadas. $\mathrm{E}$, como resultado, alguns processos erosivos se instalaram, córregos foram assoreados e diversos depósitos foram gerados. Logo, os Antropossolos da saibreira de Santa Maria em Visconde do Rio Branco, Minas Gerais, Brasil, se enquadram nessa conceituação.

Um ambiente de saibreira é onde há atividade mineral de exploração de saibro e ocorre, principalmente, devido ao baixo valor agregado do mineral, a não necessidade de tecnologias para extração e a forte demanda regional para comercialização, já que 
ele é utilizado na conservação de vias públicas. Essa atividade de fácil retirada do mineral faz com que ela ocorra de forma desordenada, sem ser fiscalizada de acordo com critérios ambientais (Brollo et al., 2005).

A extração de saibro é feita, geralmente, por pequenos empreendedores que encontram dificuldades para cumprir as exigências técnicas e legais do licenciamento ambiental e minerário (Brollo et al., 2005). A ação fiscalizadora do poder público permite o embargo das áreas que funcionam ilegalmente, mas não garante a recuperação das áreas alteradas e degradadas.

As atividades minerais, em relação à sua exploração, devem seguir a legislação aplicável, minimizando os efeitos negativos desta importante atividade econômica e maximizando os positivos, já que, neste caso, o passivo ambiental acaba sendo um problema.

As áreas que possuem extração de saibro, após serem embargadas, são abandonadas e, com isso, grande carga de sedimentos são carreados para a rede de drenagem, os processos erosivos instalados são potencializados em diferentes escalas, além da questão paisagística.

Portanto, este artigo buscou identificar e classificar os perfis de Antropossolos presentes em um ambiente de saibreira abandonada, a influência dos antigos e atuais processos erosivos na área, bem como os impactos ambientais negativos sobre a paisagem.

\section{Caracterização da área de estudo}

A área de estudo é um ambiente de saibreira (Figuras 1 e 2) localizada no distrito de Santa Maria, no município de Visconde de Rio de Branco, mesorregião da Zona da Mata em Minas Gerais (MG), Brasil.

O saibro é "um material formado a partir da decomposição in situ do granito ou do gnaisse, com a remoção de silicatos aluminosos hidratados (argila) que são levados pelas águas do lençol de escoamento superficial (...)" (Guerra e Guerra, 2008). Saibreira é um local para a retirada de saibro.

A área em questão serviu para retirada do material utilizado na pavimentação e aterros no município de Visconde do Rio Branco (MG). Ressalta-se que não existem dados públicos de quando foi iniciada a retirada do material na área e em função da ausência de licença ambiental, a exploração foi embargada e abandonada.

A história da atividade econômica em Visconde do Rio Branco é de grande importância para compreender também a existência dessa saibreira, pois, a principal fonte econômica municipal ao longo dos anos foi a produção de cana-de-açúcar e posteriormente a pastagem (Visconde do Rio Branco, 2020). Para melhorar e facilitar o transporte das mercadorias agrícolas produzidas na região, o saibro retirado era utilizado na pavimentação das estradas rurais, contribuindo para a perenidade do escoamento das produções, das mercadorias, além do deslocamento das pessoas. 


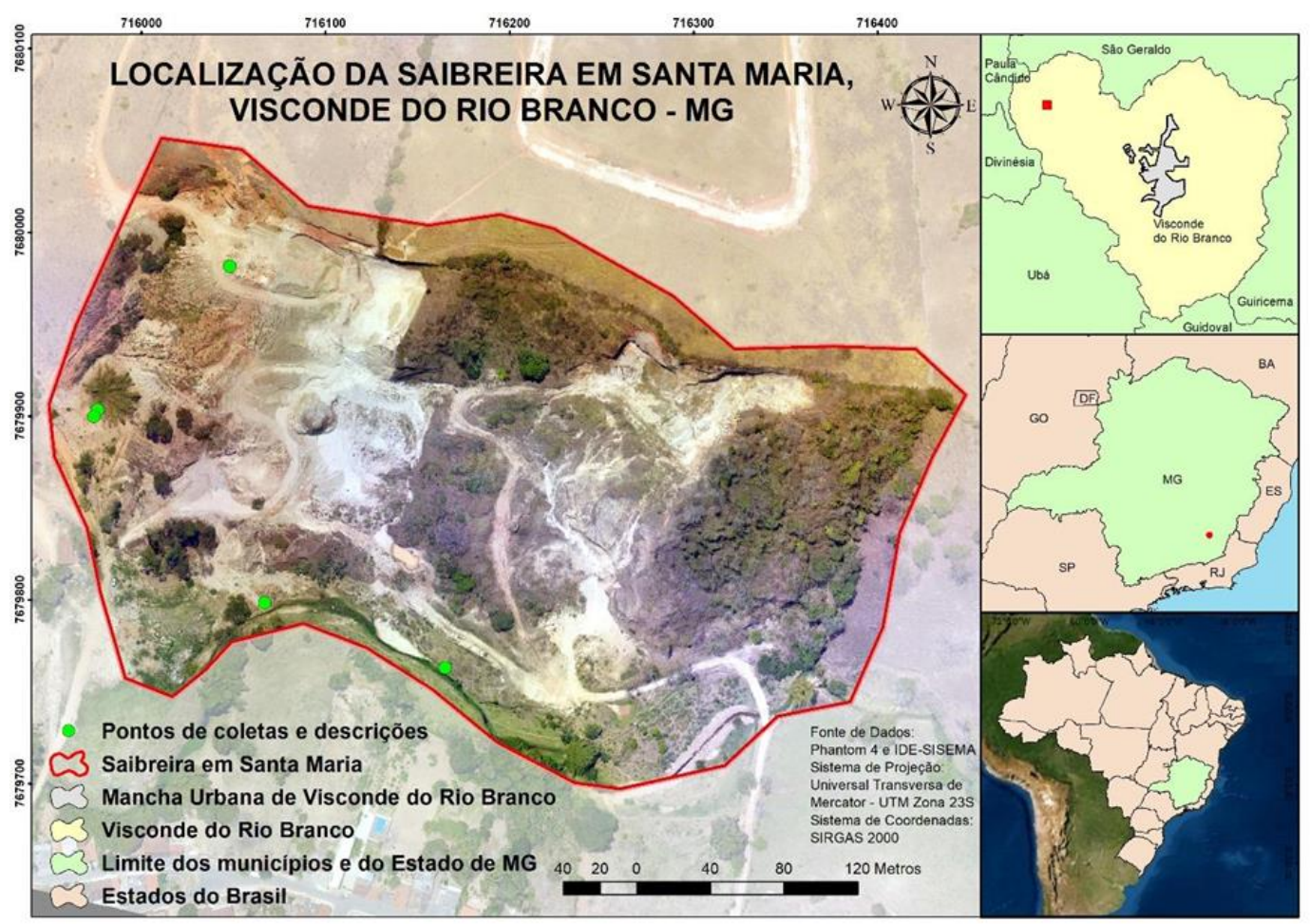

Figura 1: Mapa de Localização da área de estudo.

Fonte: Autores (2019).

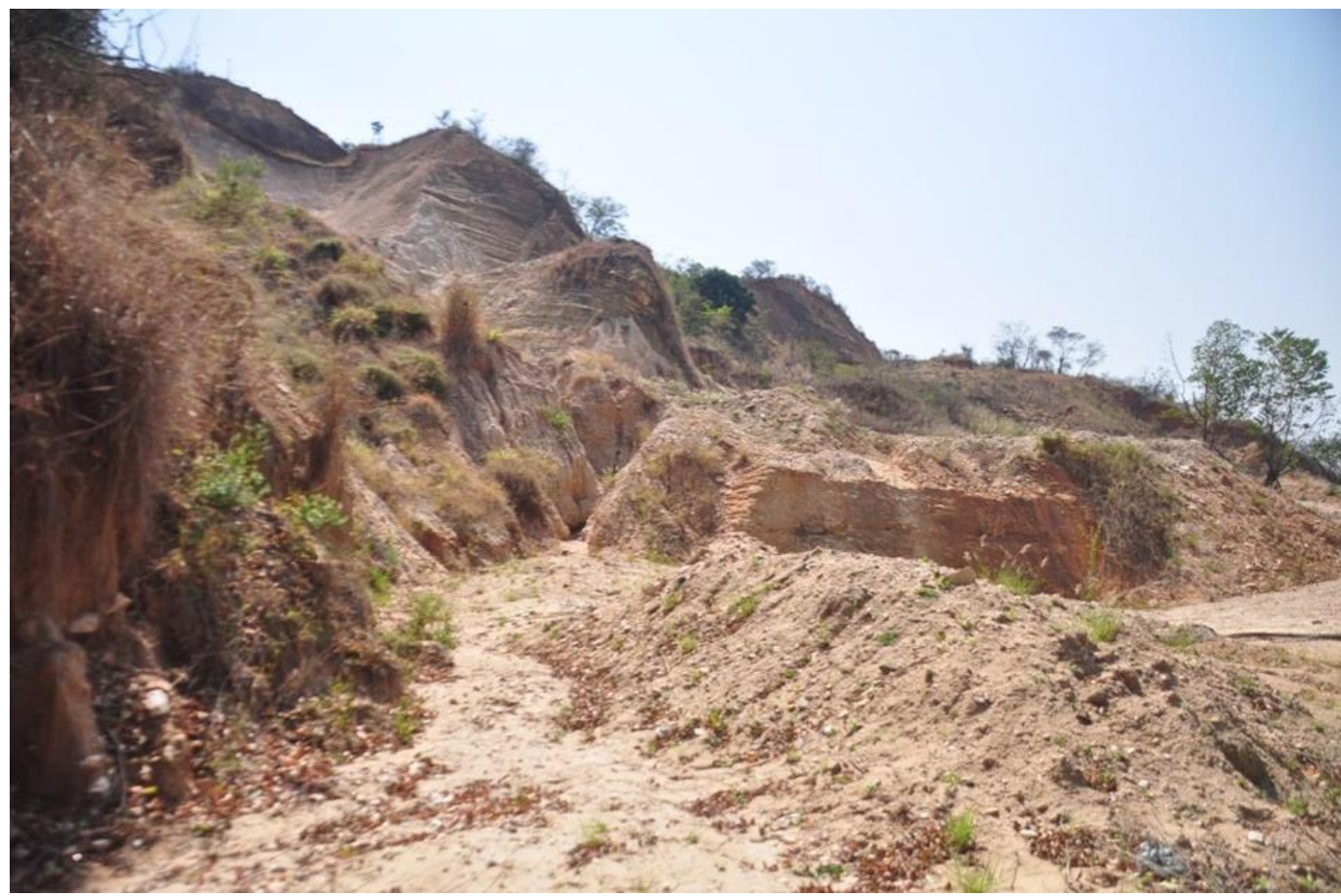

Figura 2: Local da saibreira em Santa Maria, Visconde do Rio Branco, Minas Gerais, Brasil. Fonte: Autores (2019).

Houve grande perda da biodiversidade na área, gerada pelo desmatamento, potencializado por essas atividades produtivas (Sousa, 2019). A forte ação antrópica, como a mineração e as atividades agrícolas na área, determinaram a degradação da 
antiga cobertura vegetal e, como consequência disso, os rios e as nascentes foram assoreados, como por exemplo o Ribeirão Santa Maria, que corre no sopé da saibreira, apresentando-se o entorno do seu leito muito assoreado (Figura 3).

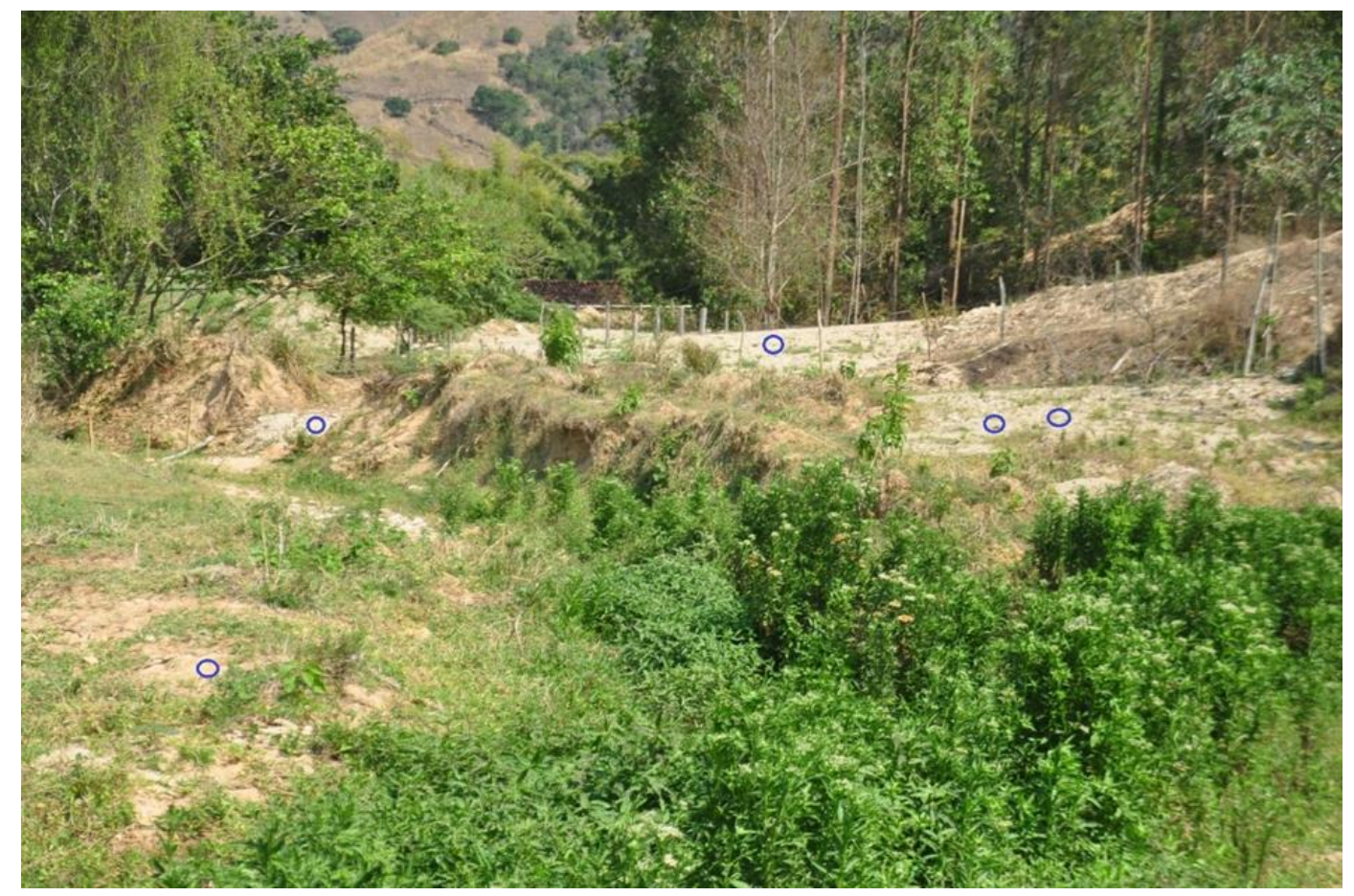

Figura 3: Na figura pode-se identificar (marcados por círculos azul-escuro) parte do material que é depositado na parte baixa da saibreira. No canto inferior direito é possível identificar o desenvolvimento de vegetação (regeneração natural).

Fonte: Autores (2019).

De acordo com a carta "Folha Viçosa - SE.23-X-B-V" disponibilizada pelo Serviço Geológico do Brasil (CPRM, 2006), a geologia da área é caracterizada por apresentar contato litológico entre Pegmatitos de granulação média a muito grossa, datados do Neoproterozóico, compostos, principalmente, por feldspato potássico, quartzo e micas, apresentando contato intrusivo com os ortognaisses do Complexo Mantiqueira, que são compostos, principalmente, por biotita, plagioclásios e quartzo, datados do Paleoproterozóico (CPRM, 2006). A presença de Pegmatito ocorre na forma de stocks, diques e veios (Figura 4) (CPRM et al., 2006). Em campo também foi possível identificar a presença de diabásio.

De acordo com o Mapa de Solos do Estado de Minas Gerais (UFV, 2010), com escala de 1:650.000, os solos presentes na área são o Argissolo Vermelho-Amarelo eutrófico (PVAe) e o Cambissolo Háplico Tb eutrófico (CXbe). A área está inserida no Domínio Morfoclimático dos Mares de Morros, caracterizada por morros arredondados e mamelonares devido ao processo de convexização extensiva e forte decomposição de rochas cristalinas (AB'SABER, 2003). 


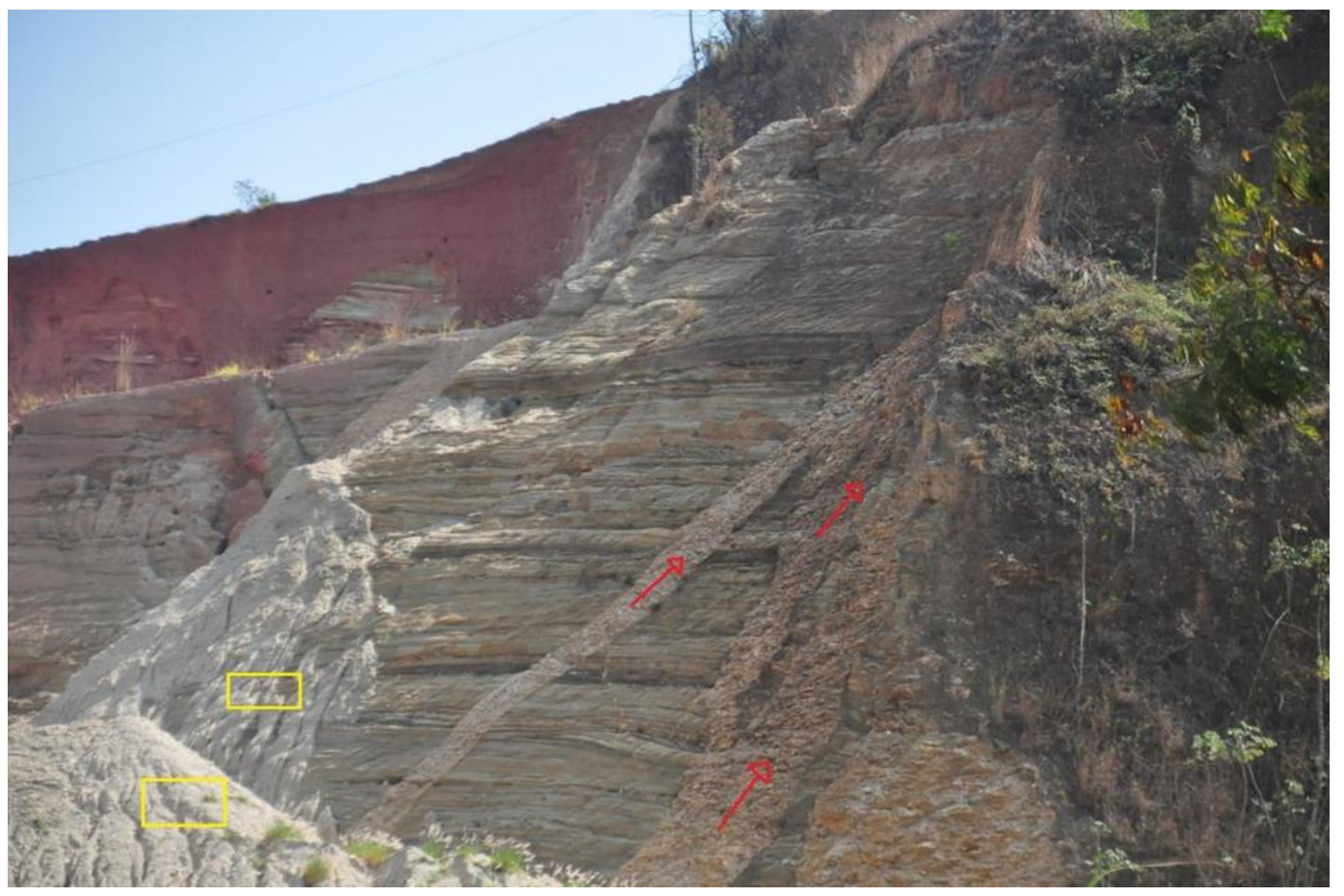

Figura 4: Na figura é possível identificar o dique de Pegmatito no centro da imagem (setas em vermelho) entranhado na estrutura gnáissica. Pode-se identificar também a metamorfização da estrutura gnáissica no canto inferior esquerdo (retângulos amarelados) e no canto superior esquerdo há o desenvolvimento de um "solo natural" (perfil avermelhado).

Fonte: Autores. (2019).

\section{Materiais e métodos}

Ao todo foram abertos 5 perfis de Antropossolos (Figura 1) e coletadas amostras dos horizontes descritos. Os locais escolhidos foram determinados para representar mais fielmente as condições da área e são eles: o sopé da encosta; os terraços fluviais; o terço médio da encosta; e as áreas de acúmulo de material carreado (bacias de decantação) antropicamente estabelecidas.

Ao final da coleta foram contabilizados 32 horizontes amostrados de cinco perfis. $O$ material coletado foi separado, identificado e descrito morfologicamente em campo e no laboratório de Geomorfologia do Quaternário, conforme o que é estabelecido pelo "Manual de Descrição e Coleta de Solo no Campo" (Santos et al., 2015). Foram também registradas as coordenadas geográficas por meio da utilização do aparelho de posicionamento terrestre Garmin Map 60 Csx. Ao final do dia de campo, as amostras foram colocadas em local sombreado para secagem ao ar.

Durante o levantamento em campo foi utilizado o Remotely Piloted Aircraft (RPA) Phantom 4 para obtenção de imagens com alta resolução espacial, que foram utilizadas na formulação do mapa temático representativo da área de estudo (Figura 1). O processamento das imagens do RPA foi feito no software Agisoft Photoscan (versão 1.2.4). O mapa foi confeccionado no software QGIS (versão 3.10), utilizando como base de dados o ortomosaico gerado a partir das imagens de alta resolução espacial, e os dados da Infraestrutura de Dados Espaciais do Sistema Estadual de 
Meio Ambiente e Recursos Hídricos - IDE-Sisema (Minas Gerais, 2016), do estado de Minas Gerais.

Passados alguns dias para secagem total das amostras, elas foram destorroadas e passadas pela peneira de $2 \mathrm{~mm}$ de abertura onde foram obtidas as Terras Finas Secas ao $\operatorname{Ar}$ (TSFA) (EMBRAPA, 2017). As amostras foram pesadas, identificadas e posteriormente, separadas frações representativas para envio aos laboratórios de rotina para as análises dos Antropossolos, seguindo a metodologia proposta por EMBRAPA (2017). Os materiais com tamanho maior que $2 \mathrm{~mm}$ foram descartados.

Após o recebimento dos resultados das análises laboratoriais (análises químicas e físicas), todas as informações foram organizadas em tabelas para facilitar a visualização e, posteriormente, a discussão. Cada Antropossolos foi caracterizado de acordo com a metodologia proposta por Curcio et al. (2004) (Tabela I), conciliando as informações laboratoriais com a descrição morfológica obtida em campo e a experiência dos pesquisadores envolvidos.

Tabela I: Resumo da proposta de classificação dos Antropossolos

\begin{tabular}{|c|c|}
\hline \multicolumn{2}{|r|}{ ORDEM } \\
\hline Antropossolos & $\begin{array}{c}\text { Associação de "antrhropos" }=\text { homem, com a terminação "solos"; } \\
\text { Produzido pelo ser humano }\end{array}$ \\
\hline \multicolumn{2}{|r|}{ SUBORDENS } \\
\hline Líxico & Contém detritos domésticos ou industriais \\
\hline Decapítico & Locais onde houve remoção de horizontes do solo \\
\hline Sômico & Locais onde houve adição de horizontes do solo \\
\hline Mobílico & Locais onde houve movimentação de horizontes do solo \\
\hline \multicolumn{2}{|r|}{ GRANDES GRUPOS } \\
\hline Áquico & São sujeitos a saturação por água \\
\hline Órtico & São compostos pelas condições habitualmente encontradas \\
\hline Totálico & Presentes nos locais com a retirada total do solo \\
\hline Parciálico & Presentes nos locais com a retirada de partes do solo \\
\hline Mésclico & Presentes nos locais com a mistura de horizontes do solo \\
\hline Camádico & Locais onde os materiais do solo estão dispostos em camadas \\
\hline Équico & Locais onde as camadas dispostas são semelhantes ao solo original \\
\hline Inêquico & Locais onde as camadas dispostas não são semelhantes ao solo original \\
\hline \multicolumn{2}{|r|}{ SUBGRUPOS } \\
\hline Tóxico & Estão presentes com materiais nocivos ao ambiente \\
\hline Séptico & Estão presentes com organismos patogênicos \\
\hline Eutrófico & São compostos por alta saturação por bases \\
\hline Distrófico & São compostos por baixa saturação por bases \\
\hline Alumínico & São compostos por altos teores de alumínio trocável \\
\hline Homogênicos & São constituídos uniformemente \\
\hline Heterogênicos & São constituídos desuniformemente \\
\hline Saprolítico & São decompostos ou constituídos pela rocha intemperizada \\
\hline
\end{tabular}

Fonte: Adaptado de Curcio et al. (2004).

Para auxiliar na caracterização dos Antropossolos, foi utilizada estatística descritiva, com dados de média aritmética, desvio padrão, variância e coeficiente de variação 
dos valores encontrados nas análises químicas, todos os dados foram organizados em tabelas, para compreender os valores obtidos e a distribuição de cada elemento químico.

A medição do $\mathrm{pH}$ foi utilizada como base nas interpretações das disponibilidades, variações ou ausências dos elementos químicos presentes nos Antropossolos. $\mathrm{O}$ pH tem influência direta sobre a Capacidade de Troca Catiônica (CTC - Valor T), sobre a Percentagem de Saturação por Bases (Valor V\%), sobre a Percentagem de Saturação por Alumínio (Valor m\%) e sobre a disponibilidade de macro e micronutrientes, além da atividade dos microrganismos (Novais et al., 2007).

Esta metodologia foi utilizada com base na descrição do preparo de amostras para análises químicas proposta pela EMBRAPA (2017). Quanto às análises físicas, foram utilizadas a classificação granulométrica e textural das amostras. A granulometria é fundamental para compreender como as propriedades físicas influenciam nas propriedades químicas e no processo de formação dos Antropossolos (Teixeira, 2015, p. 21). Enfatiza-se que foi optado por associar estas metodologias, já que não existe uma estabelecida para a classificação dos Antropossolos.

\section{Resultados e discussões}

Devido à gênese dos perfis, as camadas descritas apresentam descontinuidades e discrepâncias em relação à distribuição espacial dos seus elementos químicos, o que mostra a complexidade e a grande dificuldade para se classificar ambientes de formação dos depósitos tecnogênicos específicos (Oliveira et al., 2005).

Para responder a dificuldade de classificação e entender a gênese dos Antropossolos, foi utilizada a classificação morfológica proposta por Curcio et al. (2004) auxiliada pelas descrições e observações feitas em campo, além das análises químicas e físicas que contribuíram na classificação dos cinco Antropossolos, que se apresenta a seguir.

\subsection{Perfil A.1 - Antropossolo Sômico Camádico Áquico heterogêneo eutrófico}

O perfil A.1 (Figura 5), de coordenadas Y $7.679 .790 \mathrm{~m}$ e X $716.090 \mathrm{~m}$ do fuso UTM Zona 23S, encontra-se no sopé da encosta da saibreira e na proximidade do curso d'água - vale fluvial (Figura 6). Foi classificado como sômico para a subordem, devido a adição de material retirado da encosta. 
O agente antrópico como formador de ambientes: química, física e classificação de antropossolos Conceitos e Métodos em Geografia Física e Ambiente

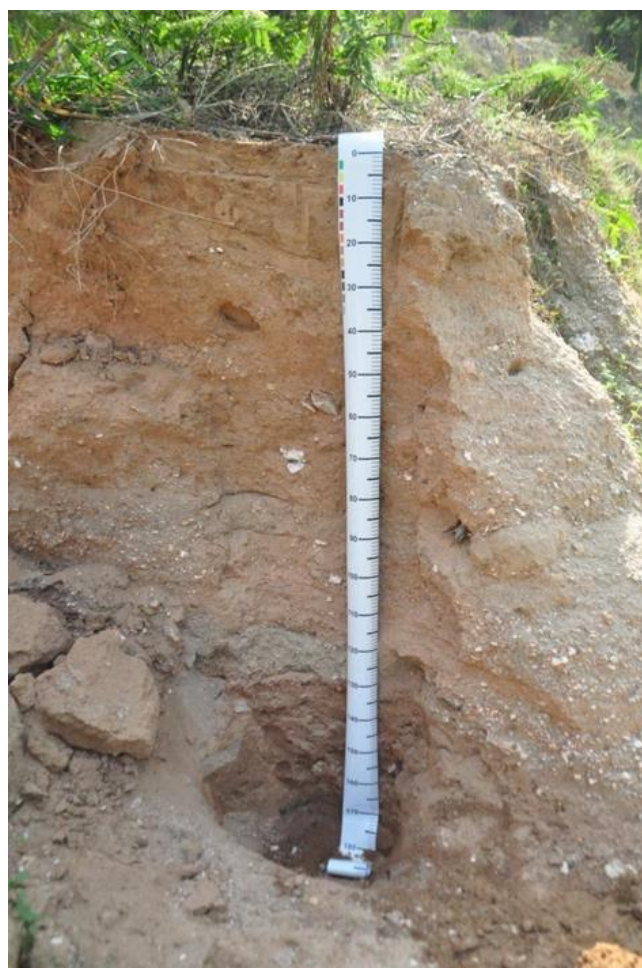

Figura 5: Perfil A.1 - Antropossolo 1. Pode-se perceber nesse perfil a presença de diferentes tamanhos de grãos de minerais e rochas, não há estrutura presente e é possível identificar as diferentes camadas de deposição e a presença de gleização na camada inferior.

Fonte: Autores (2019).

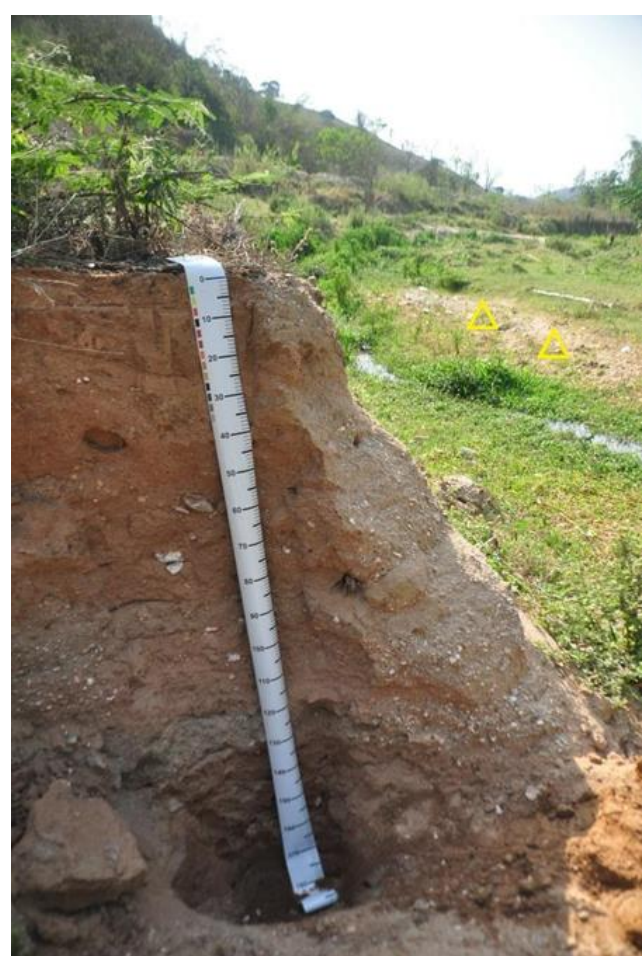

Figura 6: Perfil A.1 - Antropossolo 1 e ao fundo da imagem a proximidade ao curso d'água. Nessa área foi possível identificar a presença de descartes de resíduos humanos e também é uma área para pastagem de gado. Abaixo do canto superior direito é possível identificar um banco de areia (representado pelos triângulos amarelos), resultado das deposições de material da saibreira ao longo do curso d'água.

Fonte: Autores (2019). 
Apesar da classificação textural ter sido apenas Areia Franca (Tabela II), o perfil foi classificado como camádico para grande grupo graças à presença de diferentes camadas de deposição, comprovadas pelos diferentes tamanhos de minerais (quartzo e micas) e fragmentos de rochas, ressalta-se que há a presença de muito material solto, então com o advento das enxurradas, esse material é carreado até o curso d'água ou depositado nas margens contribuindo para aumentar o assoreamento do córrego.

$\mathrm{Na}$ camada A.1.6 foi encontrado o maior valor de $P\left(58,3 \mathrm{mg} / \mathrm{dm}^{3}\right)$ entre todas as camadas e o maior de P-Rem (52,4 mg/L) para esse perfil, o pH foi em torno de 6,19. Essas descrições indicam um material com baixa capacidade de retenção e com baixa capacidade de formação de estrutura, esses dois fatores podem contribuir para 0 aumento da eutrofização nos cursos d'água da região.

Tabela II: Resultado das análises físicas do perfil A.1 - Antropossolo 1.

\begin{tabular}{|c|c|c|c|c|c|c|}
\hline \multirow{2}{*}{ Perfil A.1 } & \multirow{2}{*}{ Horizonte (cm) } & $\begin{array}{c}\text { Areia } \\
\text { Grossa }\end{array}$ & Areia Fina & Silte & Argila & \multirow{2}{*}{ Classificação Textural } \\
\hline & & \multicolumn{4}{|c|}{ 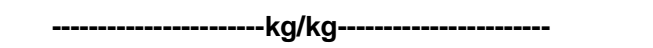 } & \\
\hline \multirow{8}{*}{ 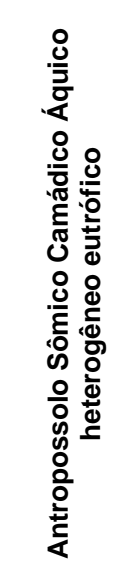 } & A.1.1 $(0-10)$ & 0,527 & 0,295 & 0,104 & 0,074 & Areia Franca \\
\hline & A.1.2 (10 - 25) & 0,415 & 0,410 & 0,088 & 0,087 & Areia Franca \\
\hline & A.1.3 (25 - 85) & 0,647 & 0,190 & 0,083 & 0,079 & Areia Franca \\
\hline & A.1.4 (85 - 95) & 0,706 & 0,164 & 0,078 & 0,052 & Areia Franca \\
\hline & A.1.5 $(95-120)$ & 0,686 & 0,177 & 0,076 & 0,060 & Areia Franca \\
\hline & A.1.6 $(120-130)$ & 0,687 & 0,168 & 0,090 & 0,055 & Areia Franca \\
\hline & A.1.7 (130 - 170) & 0,709 & 0,142 & 0,069 & 0,080 & Areia Franca \\
\hline & A.1.8 $(170+)$ & 0,658 & 0,177 & 0,089 & 0,075 & Areia Franca \\
\hline
\end{tabular}

Fonte: Autores (2020).

A partir de 170+ (camada A.1.8) é possível identificar princípio de gleização, descrito em campo e comprovado posteriormente, pelo resultado das análises químicas, que mostrou aumento brusco no teor de $\mathrm{Fe}\left(630,0 \mathrm{mg} / \mathrm{dm}^{3}\right)$ e redução no $\mathrm{pH}$ (Tabela III). A presença de gleização auxiliou a classificação como Áquico, também para grande grupo, pois ocorre a presença de lençol freático pelo menos uma vez ao ano.

Já para os subgrupos é heterogêneo, devido ao material autóctone ser diverso e composto por minerais de diferentes tipos de rocha, derivado do contato litológico a montante do perfil. Foi classificado como eutrófico devido à alta saturação por bases presentes na camada superficial (valor $\mathrm{V}=76,00 \%$ ) e valor $\mathrm{V}$ médio de $72,48 \%$ com baixo coeficiente de variação (17,60\%). Ainda sim, apresentou uma camada distrófica (A.1.8, valor $\mathrm{V} \%=42,10)$ com o maior valor de saturação por alumínio $(39,30 \%)$ e o 
menor valor para o $\mathrm{pH}(5,20)$ de todas as amostras, a camada A.1.8 é a que está em processo de gleização e sofre influência do lençol freático.

Tabela III: Resultados das análises químicas do perfil A. 1 - Antropossolo 1.

\begin{tabular}{|c|c|c|c|c|c|c|c|c|c|}
\hline \multirow{2}{*}{$\begin{array}{l}\text { PERFIL } \\
\text { A.1 }\end{array}$} & \multirow{2}{*}{ Horizonte $(\mathrm{cm})$} & \multirow{2}{*}{$\underset{\mathrm{H} 20}{\mathrm{pH}}$} & $\mathbf{P}$ & $\mathbf{K}$ & $\mathrm{Ca}$ & $\mathbf{M g}$ & $\mathrm{H}+\mathrm{Al}$ & SB & $t$ \\
\hline & & & \multicolumn{2}{|c|}{-----mg/dm³----- } & -----. & -.--... & $\mathrm{molc} / \mathrm{dm}^{3}$ & ------. & -- \\
\hline \multirow{12}{*}{ 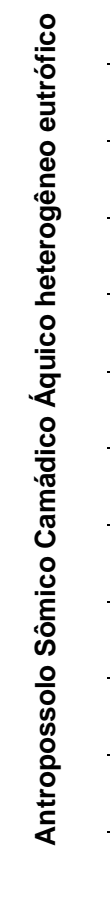 } & A.1.1 $(0-10)$ & 5,62 & 0,60 & 33,00 & 2,12 & 0,96 & 1,00 & 3,16 & 3,16 \\
\hline & A.1.2 (10 - 25) & 5,75 & 39,30 & 17,00 & 2,20 & 0,74 & 1,10 & 2,98 & 2,98 \\
\hline & A.1.3 (25 - 85) & 5,85 & 16,50 & 23,00 & 1,49 & 0,85 & 0,80 & 2,40 & 2,60 \\
\hline & A.1.4 (85 - 95) & 6,08 & 30,60 & 17,00 & 1,67 & 0,97 & 0,70 & 2,68 & 2,88 \\
\hline & A.1.5 (95 - 120) & 6,23 & 38,40 & 19,00 & 1,38 & 0,92 & 0,80 & 2,35 & 2,65 \\
\hline & $\begin{array}{c}\text { A.1.6 (120 - } \\
130)\end{array}$ & 6,19 & 58,30 & 17,00 & 1,75 & 0,85 & 0,50 & 2,64 & 2,84 \\
\hline & $\begin{array}{c}\text { A.1.7 (130 - } \\
170)\end{array}$ & 5,92 & 33,20 & 19,00 & 1,47 & 0,97 & 0,80 & 2,49 & 2,79 \\
\hline & A.1.8 (170+) & 5,20 & 9,20 & 42,00 & 0,95 & 0,47 & 2,10 & 1,53 & 2,52 \\
\hline & Média & 5,86 & 28,26 & 23,38 & 1,63 & 0,84 & 0,98 & 2,53 & 2,80 \\
\hline & Desvio Padrão & 0,33 & 18,61 & 9,26 & 0,41 & 0,17 & 0,49 & 0,49 & 0,21 \\
\hline & Variância & 0,11 & 346,23 & 85,70 & 0,16 & 0,03 & 0,24 & 0,24 & 0,04 \\
\hline & $\begin{array}{c}\text { Coeficiente de } \\
\text { Variação }\end{array}$ & 5,78 & 65,84 & 39,60 & 24,90 & 20,18 & 50,17 & 19,52 & 7,52 \\
\hline \multirow{2}{*}{$\begin{array}{l}\text { PERFIL } \\
\text { A.1 }\end{array}$} & \multirow{2}{*}{ Horizonte $(\mathrm{cm})-$} & $\mathbf{T}$ & v & m & P-Rem & $\mathrm{Zn}$ & $\mathrm{Fe}$ & Mn & $\mathrm{Cu}$ \\
\hline & & $\begin{array}{c}\mathrm{cmolc} / \\
\mathrm{dm}^{3}\end{array}$ & ----- & ----- & $\mathrm{mg} / \mathrm{L}$ & -..-- & $---m g / d^{3}$ & 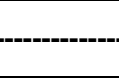 & \\
\hline \multirow{11}{*}{ 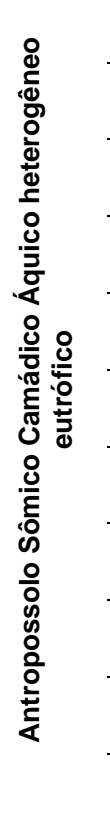 } & A.1.1 $(0-10)$ & 4,16 & 76,00 & 0,00 & 43,20 & 1,67 & 131,50 & 38,30 & 1,34 \\
\hline & A.1.2 (10 - 25) & 4,08 & 73,00 & 0,00 & 40,50 & 2,60 & 448,20 & 62,10 & 2,55 \\
\hline & A.1.3 (25 - 85) & 3,20 & 75,00 & 7,70 & 49,00 & 1,09 & 102,40 & 18,00 & 0,76 \\
\hline & A.1.4 (85 - 95) & 3,38 & 79,30 & 6,90 & 49,80 & 1,41 & 42,00 & 8,70 & 0,46 \\
\hline & A.1.5 (95 - 120) & 3,15 & 74,60 & 11,30 & 52,20 & 1,60 & 50,90 & 9,40 & 0,58 \\
\hline & $\begin{array}{l}\text { A.1.6 (120 - } \\
130)\end{array}$ & 3,14 & 84,10 & 7,00 & 54,40 & 1,29 & 57,00 & 8,50 & 0,64 \\
\hline & $\begin{array}{c}\text { A.1.7 (130 - } \\
170)\end{array}$ & 3,29 & 75,70 & 10,80 & 49,80 & 1,49 & 54,40 & 12,80 & 0,60 \\
\hline & A.1.8 (170+) & 3,63 & 42,10 & 39,30 & 38,30 & 1,63 & 630,00 & 52,50 & 2,31 \\
\hline & Média & 3,50 & 72,48 & 10,38 & 47,15 & 1,60 & 189,55 & 26,29 & 1,16 \\
\hline & Desvio Padrão & 0,41 & 12,75 & 12,44 & 5,78 & 0,45 & 223,19 & 21,63 & 0,83 \\
\hline & Variância & 0,17 & 162,62 & 154,80 & 33,38 & 0,20 & $49.812,97$ & 467,92 & 0,69 \\
\hline
\end{tabular}

Fonte: Autores (2020). 
Para esse perfil, a camada A.1.8 ainda apresentou os menores teores de $P(9,2$ $\left.\mathrm{mg} / \mathrm{dm}^{3}\right)$, Ca $\left(0,95 \mathrm{cmolc} / \mathrm{dm}^{3}\right)$ e $\mathrm{Mg}\left(0,47 \mathrm{cmolc} / \mathrm{dm}^{3}\right)$. Macronutrientes como $\mathrm{P}, \mathrm{Ca} \mathrm{e}$ Mg são menos disponíveis em $\mathrm{pH}$ menores que 5,5. Também, houve o maior teor de $\mathrm{Fe}\left(630 \mathrm{mg} / \mathrm{dm}^{3}\right)$ de todas as amostras analisadas. Por outro lado, na camada A.1.6 foi obtido o maior valor de $\mathrm{K}\left(42 \mathrm{mg} / \mathrm{dm}^{3}\right)$, muito relacionado ao $\mathrm{pH}$ de 6,16 . Já na camada A.1.2, com o pH em torno de 5,75, não foram encontrados valores de saturação por alumínio ( $\mathrm{m} \%)$ e foram registrados os maiores valores de $\mathrm{Zn}(2,60$ $\left.\mathrm{mg} / \mathrm{dm}^{3}\right)$ e $\mathrm{Cu}\left(2,55 \mathrm{mg} / \mathrm{dm}^{3}\right)$ de todas as amostras analisadas. Micronutrientes como $\mathrm{Zn}$ e $\mathrm{Cu}$ são mais disponíveis em pH menores que 6 e o Alumínio trocável é neutralizado em $\mathrm{pH}$, medido em água, maior que 5,5.

\subsection{Perfil A.2 - Antropossolo Sômico Camádico Áquico heterogêneo eutrófico}

O perfil A.2 (Figura 7), de coordenadas $Y 7.679 .754 \mathrm{~m}$ e $X 716.156 \mathrm{~m}$ do fuso UTM Zona 23S, encontra-se entre o terraço fluvial e o leito menor (Figura 8). Foi classificado para subordem como sômico, devido a presença de material retirado da saibreira e depositado na margem do curso d'água

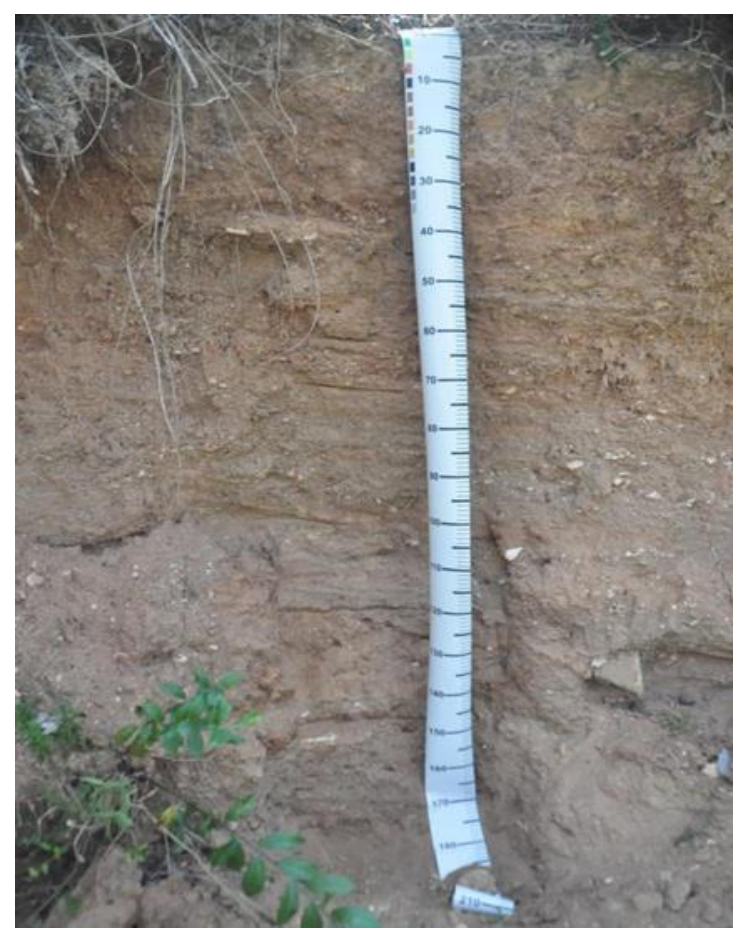

Figura 7: Perfil A.2 - Antropossolo 2. O perfil foi aberto entre o terraço fluvial e o leito menor. É possível identificar a presença de raízes e camadas distintas de deposição, além de grãos de rochas e minerais de diferentes tamanhos, além de apresentar sinais de gleização a partir de $145 \mathrm{~cm}$.

Fonte: Autores (2019). 


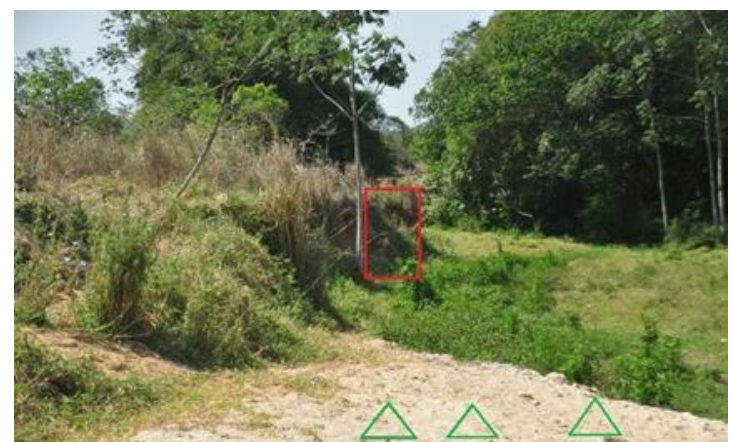

Figura 8: Local onde foi aberto o perfil A.2 - Antropossolo 2 (representado na imagem pelo retângulo vermelho). No canto inferior é possível observar resquícios do material depositado na parte baixa de onde está a Saibreira e que causa assoreamento no córrego (representados pelos triângulos verdes).

Fonte: Autores (2019).

Para o grande grupo, foi classificado como camádico e áquico. Camádico devido a presença de camadas divergentes, existe processo de formação de estrutura com raízes chegando até $60 \mathrm{~cm}$ de profundidade e também há camadas distintas e sobrepostas, com presença de grãos de minerais de diferentes tamanhos e sinal de gleização a partir de 145+. É áquico pela presença de lençol freático.

A classificação textural varia de Franco-Argilo-Arenosa, Franco-Arenosa a Areia Franca (Tabela IV). Para subgrupo, foi classificado como heterogêneo, devido a estar em uma área de contato litológico e apresentar material autóctone diverso. É eutrófico, a saturação por bases na camada superficial foi de $73,90 \%$ e o valor médio de $V$ foi de $69,91 \%$. O coeficiente de variação também foi baixo: $10,87 \%$.

Tabela IV: Resultados das análises físicas do perfil A.2 - Antropossolo 2.

\begin{tabular}{|c|c|c|c|c|c|c|}
\hline \multirow{2}{*}{ Perfil A.2 } & \multirow{2}{*}{ Horizonte (cm) } & $\begin{array}{c}\text { Areia } \\
\text { Grossa }\end{array}$ & Areia Fina & Silte & Argila & \multirow{2}{*}{$\begin{array}{c}\text { Classificação } \\
\text { Textural }\end{array}$} \\
\hline & & \multicolumn{4}{|c|}{ - } & \\
\hline \multirow{8}{*}{ 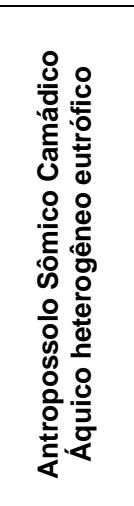 } & A.2.1 (0 - 15) & 0,247 & 0,267 & 0,277 & 0,210 & $\begin{array}{c}\text { Franco-Argilo- } \\
\text { Arenosa }\end{array}$ \\
\hline & A.2.2(15 - 40) & 0,437 & 0,203 & 0,160 & 0,200 & $\begin{array}{c}\text { Franco-Argilo- } \\
\text { Arenosa }\end{array}$ \\
\hline & A.2.3 $(40-60)$ & 0,538 & 0,234 & 0,095 & 0,134 & Franco-Arenosa \\
\hline & A.2.4 $(60-70)$ & 0,573 & 0,155 & 0,107 & 0,165 & Franco-Arenosa \\
\hline & A.2.5 $(70-110)$ & 0,573 & 0,227 & 0,070 & 0,130 & Franco-Arenosa \\
\hline & A.2.6 (110 - 130) & 0,548 & 0,257 & 0,089 & 0,107 & Franco-Arenosa \\
\hline & A.2.7 $(130-150)$ & 0,515 & 0,240 & 0,109 & 0,136 & Franco-Arenosa \\
\hline & A.2.8 (150+) & 0,668 & 0,172 & 0,065 & 0,095 & Areia-Franca \\
\hline
\end{tabular}

Fonte: Autores (2020).

Na camada A.2.1 foram encontrados os maiores teores de $\mathrm{Ca}\left(3,54 \mathrm{cmolc} / \mathrm{dm}^{3}\right)$ e K $\left(54 \mathrm{mg} / \mathrm{dm}^{3}\right)$ e o menor teor de P-rem $(38,3 \mathrm{mg} / \mathrm{L})$ de todas as amostras analisadas, o 
pH é de 5,54 e não foi encontrado valor de saturação por alumínio (m\%). Há processo de formação de estrutura na camada superficial.

A camada A.2.8, com pH em torno de 5,62 (Tabela V), apresenta processo de gleização, possui os menores valores de $\mathrm{Ca}\left(0,93 \mathrm{cmolc} / \mathrm{dm}^{3}\right)$ e $\mathrm{Mg}\left(0,27 \mathrm{cmolc} / \mathrm{dm}^{3}\right)$ de todas as análises, também tem o menor valor de saturação por bases e o maior de Fe $\left(250,80 \mathrm{mg} / \mathrm{dm}^{3}\right)$, para esse perfil.

Tabela V: Resultados das análises químicas do perfil A. 2 - Antropossolo 2.

\begin{tabular}{|c|c|c|c|c|c|c|c|c|c|c|}
\hline \multirow{2}{*}{$\begin{array}{l}\text { Perfil } \\
\text { A.2 }\end{array}$} & \multirow{2}{*}{ Horizonte (cm) } & \multirow{2}{*}{\multicolumn{2}{|c|}{$\begin{array}{c}\mathrm{pH} \\
\mathrm{H} 2 \mathrm{O}\end{array}$}} & $\mathbf{P}$ & $\mathrm{K}$ & $\mathrm{Ca}$ & $\mathbf{M g}$ & $\mathrm{H}+\mathrm{Al}$ & SB & t \\
\hline & & & & \multicolumn{2}{|c|}{-----mg/dm³---- } & \multicolumn{5}{|c|}{ - cmolc/dm³3 } \\
\hline \multirow{12}{*}{ 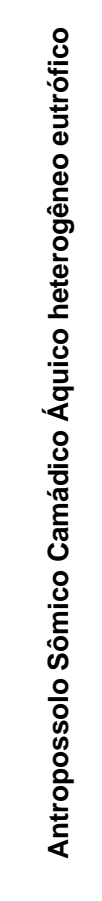 } & A.2.1 (0 - 15) & & 5,54 & 13,40 & 54,00 & 3,54 & 1,42 & 1,80 & 5,10 & 5,10 \\
\hline & A.2.2(15 - 40) & & 5,60 & 2,20 & 38,00 & 2,26 & 0,77 & 1,10 & 3,13 & 3,33 \\
\hline & A.2.3 $(40-60)$ & & 5,71 & 3,10 & 27,00 & 1,74 & 0,61 & 1,10 & 2,42 & 2,62 \\
\hline & A.2.4 $(60-70)$ & & 5,60 & 1,10 & 27,00 & 1,59 & 0,59 & 0,80 & 2,25 & 2,45 \\
\hline & A.2.5 $(70-110)$ & & 5,70 & 2,40 & 17,00 & 1,29 & 0,54 & 0,70 & 1,87 & 1,87 \\
\hline & A.2.6 $(110-130)$ & & 5,75 & 1,90 & 19,00 & 1,93 & 0,67 & 0,80 & 2,65 & 2,85 \\
\hline & A.2.7 $(130-150)$ & & 5,69 & 1,40 & 17,00 & 1,53 & 0,58 & 1,10 & 2,15 & 2,35 \\
\hline & A. $2.8(150+)$ & & 5,62 & 2,60 & 15,00 & 0,93 & 0,27 & 1,10 & 1,24 & 1,63 \\
\hline & Média & & 5,65 & 3,51 & 26,75 & 1,85 & 0,68 & 1,06 & 2,60 & 2,78 \\
\hline & Desvio Padrão & & 0,07 & 4,05 & 13,40 & 0,79 & 0,33 & 0,34 & 1,15 & 1,08 \\
\hline & Variância & & 0,01 & 16,37 & 179,64 & 0,62 & 0,11 & 0,12 & 1,32 & 1,17 \\
\hline & \multicolumn{2}{|l|}{$\begin{array}{l}\text { Coeficiente de } \\
\text { Variação }\end{array}$} & 1,26 & 115,20 & 50,11 & 42,69 & 48,57 & 32,19 & 44,25 & 38,91 \\
\hline \multirow[b]{2}{*}{$\begin{array}{l}\text { Perfil } \\
\text { A.2 }\end{array}$} & \multirow[b]{2}{*}{$\begin{array}{l}\text { Horizonte } \\
\text { (cm) }\end{array}$} & \multicolumn{2}{|l|}{$\mathbf{T}$} & $\mathbf{v}$ & $\mathbf{m}$ & P-rem & $\mathrm{Zn}$ & $\mathrm{Fe}$ & Mn & $\mathrm{Cu}$ \\
\hline & & \multicolumn{2}{|c|}{$\begin{array}{l}\mathrm{cmol} \\
\mathrm{c} / \mathrm{dm}\end{array}$} & \multicolumn{2}{|c|}{--------\%-------- } & $\mathrm{mg} / \mathrm{L}$ & \multicolumn{3}{|c|}{--------------mg/dm³_--------------- } & \\
\hline \multirow{7}{*}{ 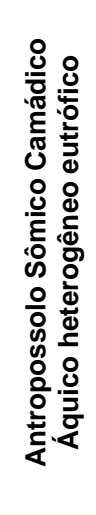 } & A.2.1 (0 - 15) & 6,90 & & 73,90 & 0,00 & 38,30 & 2,42 & 138,50 & 78,70 & 1,77 \\
\hline & $\begin{array}{l}\text { A.2.2(15 - } \\
40)\end{array}$ & 4,23 & & 74,00 & 6,00 & 39,00 & 1,28 & 97,50 & 40,80 & 1,09 \\
\hline & $\begin{array}{l}\text { A.2.3 (40 - } \\
60)\end{array}$ & 3,52 & & 68,80 & 7,60 & 44,70 & 1,08 & 67,40 & 26,70 & 0,80 \\
\hline & $\begin{array}{l}\text { A.2.4 (60 - } \\
70)\end{array}$ & 3,05 & & 73,80 & 8,20 & 42,70 & 1,14 & 59,50 & 28,60 & 0,94 \\
\hline & $\begin{array}{c}\text { A.2.5 (70 - } \\
110)\end{array}$ & 2,57 & & 72,80 & 0,00 & 48,60 & 1,07 & 56,00 & 21,40 & 0,73 \\
\hline & $\begin{array}{l}\text { A.2.6 (110 - } \\
130)\end{array}$ & 3,45 & & 76,80 & 7,00 & 49,00 & 0,95 & 57,10 & 13,10 & 0,81 \\
\hline & $\begin{array}{l}\text { A.2.7 (130 - } \\
150)\end{array}$ & 3,25 & & 66,20 & 8,50 & 42,80 & 0,58 & 144,30 & 17,30 & 1,41 \\
\hline
\end{tabular}


O agente antrópico como formador de ambientes: química, física e classificação de antropossolos Conceitos e Métodos em Geografia Física e Ambiente

\begin{tabular}{ccccccccc}
\hline A.2.8 (150+) & 2,34 & 53,00 & 23,90 & 44,30 & 1,15 & 250,80 & 33,60 & 1,88 \\
\hline Média & 3,66 & 69,91 & 7,65 & 43,68 & 1,21 & 108,89 & 32,53 & 1,18 \\
\hline $\begin{array}{c}\text { Desvio } \\
\text { Padrão }\end{array}$ & 1,43 & 7,60 & 7,42 & 3,90 & 0,53 & 67,65 & 20,65 & 0,45 \\
\hline Variância & 2,05 & 57,79 & 55,04 & 15,22 & 0,28 & $4.577,02$ & 426,29 & 0,21 \\
\hline $\begin{array}{c}\text { Coeficiente } \\
\text { de Variação }\end{array}$ & $\begin{array}{c}39,0 \\
9\end{array}$ & 10,87 & 96,98 & 8,93 & 43,98 & 62,13 & 63,48 & 38,48 \\
\hline
\end{tabular}

Fonte: Autores (2020).

O Antropossolo Sômico Camádico Áquico heterogêneo eutrófico, ou somente perfil A.2, talvez seja aquele dos perfis descritos, que melhor têm se adaptado e evoluído a partir das condições impostas do ambiente.

\subsection{Perfil A.3 - Antropossolo Sômico Camádico heterogêneo eutrófico}

O perfil A.3 (Figura 9), de coordenadas Y $7.679 .908 \mathrm{~m}$ e X $715.978 \mathrm{~m}$ do fuso UTM Zona 23S, foi aberto no entorno de uma bacia de decantação, abaixo de um bambuzeiro (Figura 10). Foi classificado como Sômico, para subordem, devido a retirada de material dentro da bacia de decantação e incorporação nos arredores, formando assim montes de material solto, o que facilita o transporte para as partes mais baixas com as enxurradas.

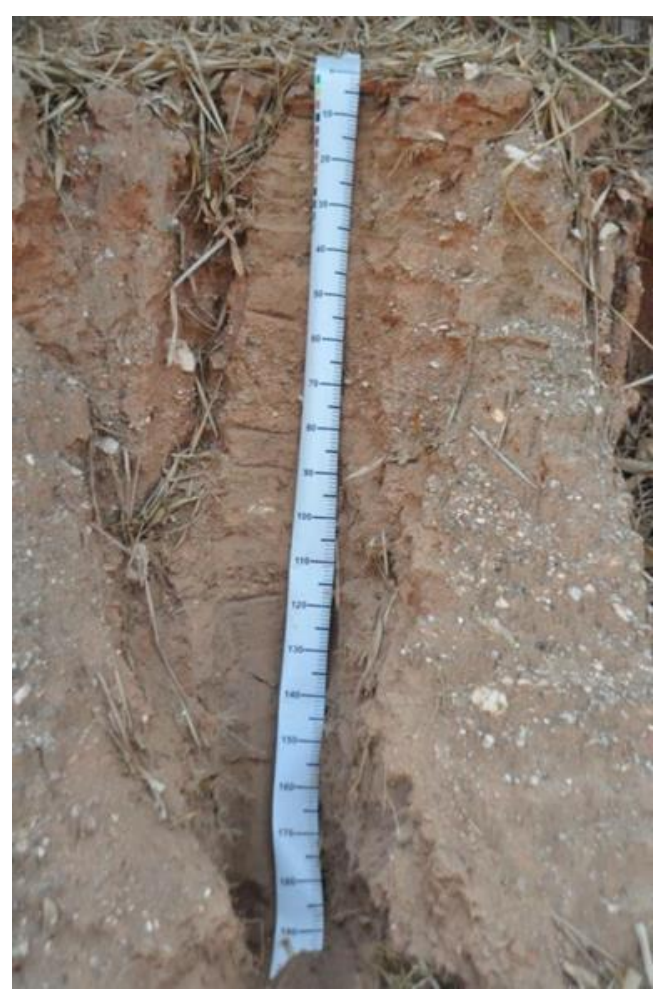

Figura 9: Perfil A.3 - Antropossolo 3. Nesse perfil é possível identificar a presença de grãos de rochas e minerais de diferentes tamanhos, há também o soterramento de folhas de bambu, identificado a partir de $55 \mathrm{~cm}$.

Fonte: Autores (2019). 


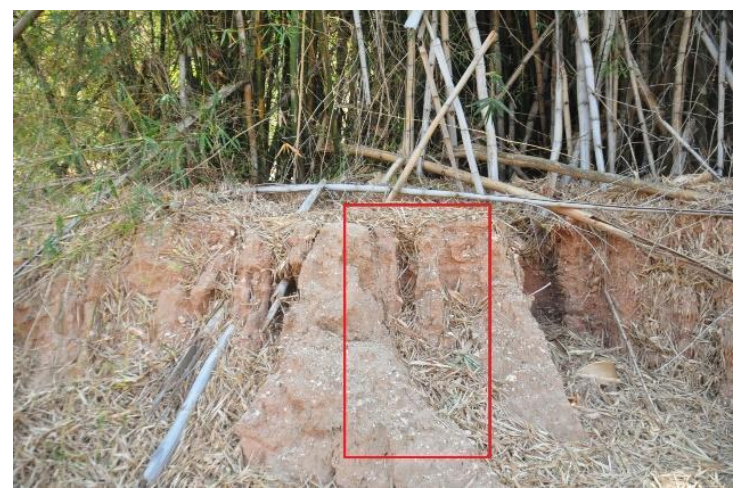

Figura 10: O local de abertura do perfil A.3 - Antropossolo 3 (representado pelo retângulo vermelho).

Foi aberto abaixo de um bambuzeiro. Esse local está nos arredores de uma antiga bacia de decantação. Foi possível encontrar folhas de bambu soterradas, indicando que a atividade erosiva na área é presente e intensa.

Fonte: Autores (2019).

Para grande grupo, é Camádico, em função de diferenças nas camadas de deposição observada pelo tamanho dos grãos de minerais e rochas presentes no perfil, além do que, a partir da camada A.3.4 foi observado o soterramento de folhas de bambu e presença de raízes, o que explica a deposição desordenada de material.

Sua classificação textural varia de Franco-Arenosa a Areia Franca (Tabela VI). A heterogeneidade (subgrupo) do perfil é marcada também por estar presente em área de contato litológico e o material ser diverso. É eutrófico devido ao valor médio de V\% igual a 76,86\%. A camada A.3.2 apresentou valor de $\mathrm{Mg}$ igual a $1,44 \mathrm{cmolc} / \mathrm{dm}^{3} \mathrm{e} \mathrm{pH}$ de 5,87, já na camada A.3.8 o valor de $\mathrm{Mn}$ foi de $99,4 \mathrm{mg} / \mathrm{dm}^{3}$ e $\mathrm{pH} 5,47$. Os valores de $\mathrm{Mg}$ e $\mathrm{Mn}$ desse perfil, foram os maiores encontrados nas amostras analisadas. A presença de Mn confirma também a heterogeneidade do material ali depositado.

Tabela VI: Resultados das análises físicas do perfil A.3 - Antropossolo 3.

\begin{tabular}{|c|c|c|c|c|c|c|}
\hline \multirow{2}{*}{ Perfil A.3 } & \multirow{2}{*}{$\begin{array}{l}\text { Horizonte } \\
\text { (cm) }\end{array}$} & $\begin{array}{c}\text { Areia } \\
\text { Grossa }\end{array}$ & Areia Fina & Silte & Argila & \multirow{2}{*}{$\begin{array}{l}\text { Classificação } \\
\text { Textural }\end{array}$} \\
\hline & & \multicolumn{4}{|c|}{ 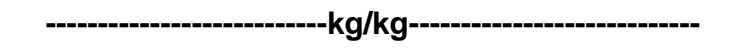 } & \\
\hline \multirow{9}{*}{ 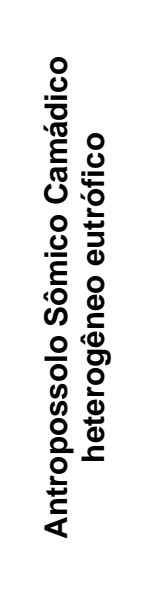 } & A.3.1 (0 - 10) & 0,557 & 0,163 & 0,107 & 0,173 & Franco-Arenosa \\
\hline & A.3.2 $(10-20)$ & 0,561 & 0,172 & 0,130 & 0,137 & Franco-Arenosa \\
\hline & A.3.3 (20 - 55) & 0,661 & 0,140 & 0,105 & 0,094 & Areia Franca \\
\hline & A.3.4 (55 - 80) & 0,696 & 0,113 & 0,096 & 0,095 & Areia Franca \\
\hline & A.3.5 $(80-90)$ & 0,678 & 0,152 & 0,069 & 0,102 & Areia Franca \\
\hline & $\begin{array}{c}A .3 .6(90- \\
120)\end{array}$ & 0,653 & 0,161 & 0,092 & 0,094 & Areia Franca \\
\hline & $\begin{array}{c}\text { A.3.7 (120 - } \\
155)\end{array}$ & 0,642 & 0,171 & 0,090 & 0,097 & Areia Franca \\
\hline & $\begin{array}{c}\text { A.3.8 (155 - } \\
180)\end{array}$ & 0,544 & 0,223 & 0,086 & 0,147 & Franco-Arenosa \\
\hline & A.3.9 (180+) & 0,746 & 0,100 & 0,053 & 0,102 & Areia Franca \\
\hline
\end{tabular}

Fonte: Autores (2020). 
Na camada A.3.9 foi encontrado o menor valor de $\mathrm{K}\left(13 \mathrm{mg} / \mathrm{dm}^{3}\right)$ das análises (Tabela VII). A camada A.3.8 apresentou aumento brusco no teor de Fe comparado a camada superior (A.3.7), 332,00 mg/dm³ e $52,7 \mathrm{mg} / \mathrm{dm}^{3}$, respectivamente.

Tabela VII: Resultados das análises químicas do perfil A. 3 - Antropossolo 3.

\begin{tabular}{|c|c|c|c|c|c|c|c|c|c|}
\hline \multirow{2}{*}{$\begin{array}{l}\text { Perfil } \\
\text { A.3 }\end{array}$} & \multirow{2}{*}{$\begin{array}{l}\text { Horizonte } \\
\quad(\mathrm{cm})\end{array}$} & \multirow{2}{*}{ pH H2O } & $\mathbf{P}$ & $\mathbf{K}$ & $\mathrm{Ca}$ & Mg & $\mathrm{H}+\mathrm{Al}$ & SB & $\mathbf{t}$ \\
\hline & & & \multicolumn{2}{|c|}{-----mg/dm³---- } & \multicolumn{5}{|c|}{ 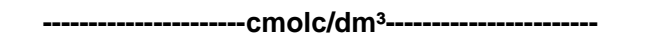 } \\
\hline \multirow{13}{*}{ 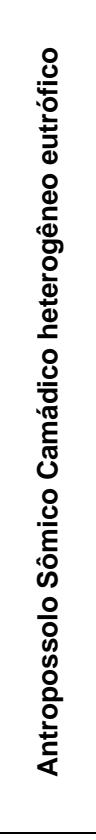 } & A.3.1 $(0-10)$ & 5,52 & 15,60 & 48,00 & 1,90 & 1,37 & 1,30 & 3,39 & 3,69 \\
\hline & A.3.2 (10 - 20) & 5,87 & 19,90 & 25,00 & 2,49 & 1,44 & 1,10 & 3,99 & 4,19 \\
\hline & A.3.3 $(20-55)$ & 5,97 & 31,40 & 23,00 & 1,83 & 1,06 & 0,80 & 2,95 & 3,25 \\
\hline & A.3.4 (55 - 80) & 5,94 & 24,90 & 21,00 & 1,66 & 1,01 & 0,70 & 2,72 & 2,92 \\
\hline & A.3.5 $(80-90)$ & 5,99 & 32,90 & 21,00 & 1,64 & 0,95 & 0,80 & 2,64 & 2,84 \\
\hline & $\begin{array}{c}\text { A.3.6 (90 - } \\
120) \\
\end{array}$ & 5,95 & 30,30 & 21,00 & 1,99 & 1,21 & 0,80 & 3,25 & 3,45 \\
\hline & $\begin{array}{c}\text { A.3.7 (120 - } \\
155)\end{array}$ & 6,01 & 19,90 & 25,00 & 1,93 & 1,17 & 1,00 & 3,16 & 3,46 \\
\hline & $\begin{array}{c}\text { A.3.8 (155 - } \\
180)\end{array}$ & 5,47 & 6,60 & 40,00 & 2,02 & 1,21 & 1,80 & 3,33 & 4,02 \\
\hline & A.3.9 $(180+)$ & 5,83 & 13,20 & 13,00 & 1,63 & 1,17 & 0,50 & 2,83 & 2,83 \\
\hline & Média & 5,84 & 21,63 & 26,33 & 1,90 & 1,18 & 0,98 & 3,14 & 3,41 \\
\hline & $\begin{array}{l}\text { Desvio } \\
\text { Padrão } \\
\end{array}$ & 0,20 & 9,00 & 10,81 & 0,27 & 0,16 & 0,39 & 0,42 & 0,50 \\
\hline & Variância & 0,04 & 80,96 & 116,75 & 0,07 & 0,03 & 0,15 & 0,17 & 0,25 \\
\hline & $\begin{array}{l}\text { Coeficiente } \\
\text { de Variação }\end{array}$ & 3,48 & 41,59 & 41,03 & 14,11 & 13,50 & 39,54 & 13,29 & 14,64 \\
\hline \multirow{2}{*}{$\begin{array}{l}\text { Perfil } \\
\text { A.3 }\end{array}$} & \multirow{2}{*}{$\begin{array}{l}\text { Horizonte } \\
\quad(\mathbf{c m})\end{array}$} & $\mathbf{T}$ & v & $\mathbf{m}$ & P-rem & $\mathrm{Zn}$ & $\mathrm{Fe}$ & Mn & $\mathrm{Cu}$ \\
\hline & & $\mathrm{cmolc} / \mathrm{dm}^{3}$ & \multicolumn{2}{|c|}{--------\%-------- } & $\mathrm{mg} / \mathrm{L}$ & \multicolumn{4}{|c|}{--------------'mg/dm³_-------------- } \\
\hline \multirow{13}{*}{ 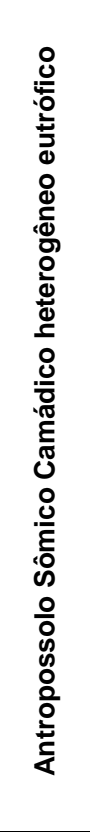 } & A.3.1 $(0-10)$ & 4,69 & 72,30 & 8,10 & 39,20 & 0,90 & 35,50 & 20,00 & 0,63 \\
\hline & A.3.2 $(10-20)$ & 5,09 & 78,40 & 4,80 & 47,10 & 0,90 & 32,20 & 12,50 & 0,52 \\
\hline & A.3.3 $(20-55)$ & 3,75 & 78,70 & 9,20 & 51,80 & 1,21 & 31,00 & 10,10 & 0,58 \\
\hline & A.3.4 (55 - 80) & 3,42 & 79,50 & 6,80 & 51,40 & 1,26 & 25,80 & 7,60 & 0,54 \\
\hline & A.3.5 $(80-90)$ & 3,44 & 76,70 & 7,00 & 50,80 & 1,77 & 41,40 & 9,90 & 0,68 \\
\hline & $\begin{array}{c}\text { A.3.6 (90 - } \\
120)\end{array}$ & 4,05 & 80,20 & 5,80 & 50,70 & 1,36 & 54,80 & 16,90 & 0,79 \\
\hline & $\begin{array}{c}\text { A.3.7 (120 - } \\
155)\end{array}$ & 4,16 & 76,00 & 8,70 & 51,40 & 1,23 & 52,70 & 22,50 & 0,72 \\
\hline & $\begin{array}{c}\text { A.3.8 (155 - } \\
180)\end{array}$ & 5,13 & 64,90 & 17,20 & 41,00 & 2,32 & 332,00 & 99,40 & 1,74 \\
\hline & A.3.9 $(180+)$ & 3,33 & 85,00 & 0,00 & 51,50 & 1,00 & 54,40 & 25,80 & 0,71 \\
\hline & Média & 4,12 & 76,86 & 7,51 & 48,32 & 1,33 & 73,31 & 24,97 & 0,77 \\
\hline & $\begin{array}{l}\text { Desvio } \\
\text { Padrão } \\
\end{array}$ & 0,71 & 5,64 & 4,55 & 4,89 & 0,46 & 97,62 & 28,60 & 0,38 \\
\hline & Variância & 0,50 & 31,84 & 20,74 & 23,91 & 0,21 & $9.528,84$ & 817,74 & 0,14 \\
\hline & $\begin{array}{l}\text { Coeficiente } \\
\text { de Variação }\end{array}$ & 17,18 & 7,34 & 60,64 & 10,12 & 34,54 & 133,15 & 114,54 & 48,88 \\
\hline
\end{tabular}

Fonte: Autores (2020). 
A explicação se dá pelo acúmulo de água que havia ali e também pela redução no valor de $\mathrm{pH}, 6,01$ para 5,47 entre as camadas vizinhas. Outro fator preponderante foi a redução nos valores do P-rem de 51,4 (mg/L) para 41,0 (mg/L), que indica a presença de um material com maior capacidade de retenção de fósforo e as análises físicas mostraram um aumento no teor de argila na camada A.3.8. Não foram encontrados sinais de gleização.

\subsection{Perfil A.4 - Antropossolo Mobílico Inêquico Tb eutrófico}

O perfil A.4 (Figura 11), de coordenadas Y $7.679 .900 \mathrm{~m}$ e X $715.974 \mathrm{~m}$ do fuso UTM Zona 23S, foi aberto em ambiente confinado, dentro da bacia de decantação (Figura 12) presente no depósito da saibreira.

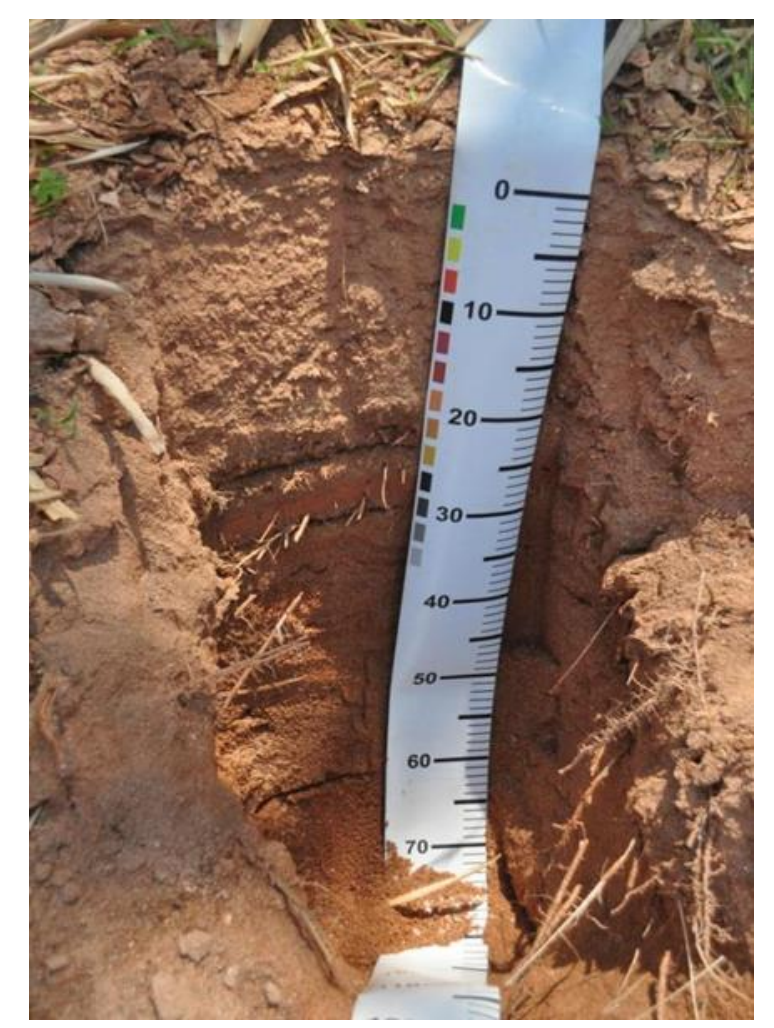

Figura 11: Perfil A.4 - Antropossolo 4. Esse perfil foi aberto em ambiente confinado. É possível identificar a presença de dois processos distintos de acumulação. O primeiro (marcado abaixo de $20 \mathrm{~cm}$ ) é resquício da antiga bacia de decantação e o segundo é resultado do atual processo erosivo e deposicional instalado após abandono da atividade minerária. É possível identificar a presença de raízes nas camadas inferiores, processo iniciado a partir de $20 \mathrm{~cm}$.

Fonte: Autores (2019).

Foi caracterizado como mobílico, para subordem, devido a decapitação de um horizonte que tinha e, posteriormente, houve deposição de material, no primeiro momento, argila, em função da bacia de decantação e após abandono da atividade de extração mineral, ocorre a deposição do material do entorno, em sua maior parte, areia. 


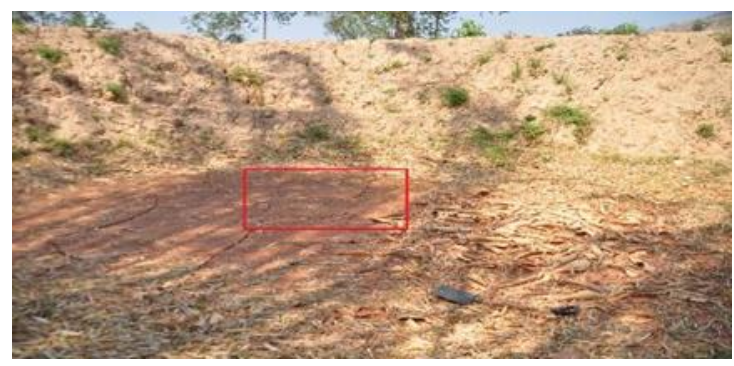

Figura 12: Local de abertura do perfil A.4 - Antropossolo 4 (representado pelo retângulo vermelho). É uma antiga bacia de decantação que atualmente se tornou uma caixa de armazenamento de sedimentos e água provindos da erosão e escoamento superficial.

Fonte: Autores (2019).

É inêquico (grande grupo) por ser constituído por camadas sem similaridade à ordem de disposição dos horizontes encontradas nos solos originais. A classificação textural variou de Franco-Arenosa a Areia Franca (Tabela VIII). A classificação de subgrupo foi Tb e eutrófico, apresenta argila de baixa atividade (Tb), em campo não foram registradas altas pegajosidades e a camada superficial (A.4.1) com V\% igual a $68,1 \%$, é o menor valor, para todos os horizontes superficiais analisados. $\mathrm{O}$ valor $\mathrm{V} \%$ médio foi de $71,83 \%$, com coeficiente de variação muito baixo $(3,35 \%)$.

Tabela VIII: Resultados das análises físicas do perfil A.4 - Antropossolo 4.

\begin{tabular}{|c|c|c|c|c|c|c|}
\hline \multirow{2}{*}{ Perfil A.4 } & \multirow{2}{*}{ Horizonte $(\mathrm{cm})$} & Areia Grossa & Areia Fina & Silte & Argila & \multirow{2}{*}{$\begin{array}{l}\text { Classificação } \\
\text { Textural }\end{array}$} \\
\hline & & \multicolumn{4}{|c|}{ - } & \\
\hline \multirow{4}{*}{ 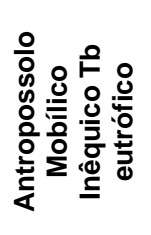 } & A.4.1 $(0-20)$ & 0,612 & 0,169 & 0,089 & 0,130 & Franco-Arenosa \\
\hline & A.4.2 (20 - 30) & 0,454 & 0,225 & 0,142 & 0,179 & Franco-Arenosa \\
\hline & A.4.3 $(30-60)$ & 0,601 & 0,210 & 0,067 & 0,122 & Franco-Arenosa \\
\hline & A.4.4 (60+) & 0,780 & 0,085 & 0,048 & 0,087 & Areia Franca \\
\hline
\end{tabular}

Fonte: Autores (2020).

É importante destacar que no horizonte A.4.2, há um maior agrupamento entre argilas, com presença de raízes e é também, um ótimo indicador da antiga bacia de decantação. Apesar do pH desse perfil variar entre 5,81 e 5,93 (Tabela IX) a disponibilidade dos elementos (macros e micros) não é expressiva, se comparada aos outros perfis. Outro fator preponderante, é que os depósitos nos arredores da bacia estão sofrendo com ravinamentos, facilitando o movimento e a deposição no interior da área abandonada, realidade apresentada pelo perfil A.3. 
Tabela IX: Resultados das análises químicas do perfil A.4 - Antropossolo 4.

\begin{tabular}{|c|c|c|c|c|c|c|c|c|c|}
\hline \multirow{2}{*}{$\begin{array}{l}\text { Perfil } \\
\text { A.4 }\end{array}$} & \multirow{2}{*}{$\begin{array}{l}\text { Horizonte } \\
\quad(\mathrm{cm})\end{array}$} & \multirow{2}{*}{ pH H2O } & $\mathbf{P}$ & $\mathrm{K}$ & $\mathrm{Ca}$ & Mg & $\mathrm{H}+\mathrm{Al}$ & SB & $\mathbf{t}$ \\
\hline & & & \multicolumn{2}{|c|}{$----m g / d^{3}----$} & \multicolumn{5}{|c|}{ 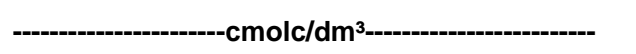 } \\
\hline \multirow{8}{*}{ 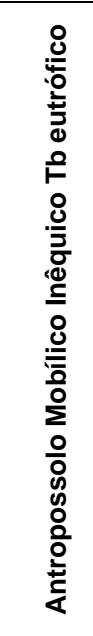 } & $\begin{array}{l}\text { A.4.1 (0 - } \\
20)\end{array}$ & 5,81 & 10,10 & 33,00 & 1,53 & 1,17 & 1,30 & 2,78 & 3,17 \\
\hline & $\begin{array}{c}\text { A.4.2 (20 - } \\
30)\end{array}$ & 5,85 & 12,10 & 38,00 & 2,23 & 1,42 & 1,50 & 3,75 & 4,14 \\
\hline & $\begin{array}{c}\text { A.4.3 (30 - } \\
60)\end{array}$ & 5,93 & 9,90 & 25,00 & 1,77 & 1,21 & 1,10 & 3,04 & 3,43 \\
\hline & A.4.4 $(60+)$ & 5,90 & 10,80 & 19,00 & 1,37 & 0,91 & 0,80 & 2,33 & 2,53 \\
\hline & Média & 5,87 & 10,73 & 28,75 & 1,73 & 1,18 & 1,18 & 2,98 & 3,32 \\
\hline & $\begin{array}{l}\text { Desvio } \\
\text { Padrão }\end{array}$ & 0,05 & 0,86 & 7,29 & 0,32 & 0,18 & 0,26 & 0,51 & 0,58 \\
\hline & Variância & 0,00 & 0,74 & 53,19 & 0,11 & 0,03 & 0,07 & 0,26 & 0,33 \\
\hline & $\begin{array}{c}\text { Coeficiente } \\
\text { de } \\
\text { Variação }\end{array}$ & 0,78 & 8,03 & 25,37 & 18,81 & 15,40 & 22,01 & 17,29 & 17,39 \\
\hline \multirow{2}{*}{$\begin{array}{c}\text { Perfil } \\
\text { A. } 4\end{array}$} & \multirow{2}{*}{$\begin{array}{l}\text { Horizonte } \\
\quad(\mathrm{cm})\end{array}$} & $\mathbf{T}$ & $\mathbf{v}$ & m & P-rem & $\mathrm{Zn}$ & $\mathrm{Fe}$ & Mn & $\mathrm{Cu}$ \\
\hline & & $\mathrm{cmolc} / \mathrm{dm}^{3}$ & \multicolumn{2}{|c|}{--------\%-------- } & $\mathrm{mg} / \mathrm{L}$ & \multicolumn{4}{|c|}{ 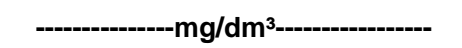 } \\
\hline \multirow{8}{*}{ 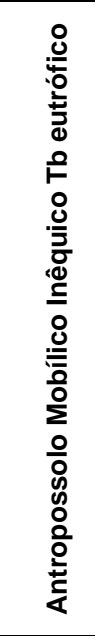 } & $\begin{array}{l}\text { A.4.1 (0 - } \\
20)\end{array}$ & 4,08 & 68,10 & 12,30 & 43,80 & 1,09 & 19,20 & 10,00 & 0,47 \\
\hline & $\begin{array}{l}\text { A.4.2(20 - } \\
30)\end{array}$ & 5,25 & 71,40 & 9,40 & 41,50 & 0,73 & 37,10 & 24,40 & 0,64 \\
\hline & $\begin{array}{c}\text { A.4.3(30 - } \\
60)\end{array}$ & 4,14 & 73,40 & 11,40 & 42,90 & 0,65 & 16,50 & 12,90 & 0,45 \\
\hline & A.4.4 $(60+)$ & 3,13 & 74,40 & 7,90 & 49,80 & 0,86 & 16,40 & 19,70 & 0,39 \\
\hline & Média & 4,15 & 71,83 & 10,25 & 44,50 & 0,83 & 22,30 & 16,75 & 0,49 \\
\hline & $\begin{array}{l}\text { Desvio } \\
\text { Padrão }\end{array}$ & 0,75 & 2,41 & 1,72 & 3,17 & 0,17 & 8,62 & 5,65 & 0,09 \\
\hline & Variância & 0,56 & 5,79 & 2,94 & 10,04 & 0,03 & 74,28 & 31,90 & 0,01 \\
\hline & $\begin{array}{c}\text { Coeficiente } \\
\text { de } \\
\text { Variação }\end{array}$ & 18,09 & 3,35 & 16,74 & 7,12 & 20,00 & 38,65 & 33,72 & 19,04 \\
\hline
\end{tabular}

Fonte: Autores (2020).

\subsection{Perfil A.5 - Antropossolo Mobílico Inêquico Tb eutrófico}

O perfil A.5 (Figura 13), de coordenadas $Y 7.679 .986 \mathrm{~m}$ e $X 716.047 \mathrm{~m}$ do fuso UTM Zona 23S, foi aberto no terço médio da encosta (Figura 14). 


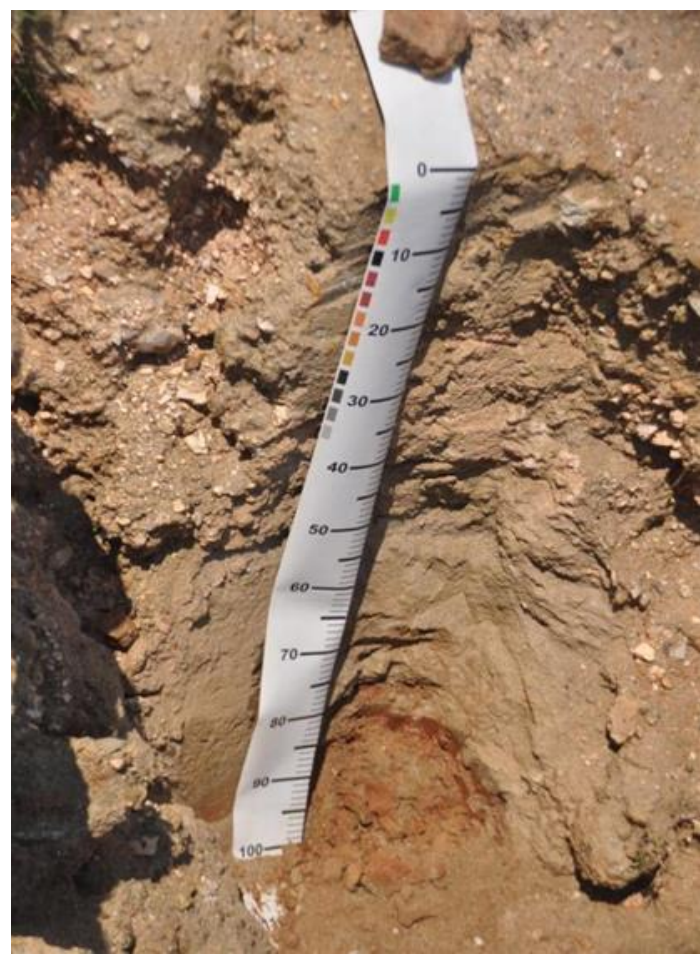

Figura 13: Perfil A.5 - Antropossolo 5. Esse perfil apresentou a incorporação de material sobre um horizonte natural que foi decapitado e não apresentou a disposição original. É possível identificar também a presença de grãos de minerais e rochas de diferentes tamanhos, indicando que o material foi apenas descartado ali.

Fonte: Autores (2019).

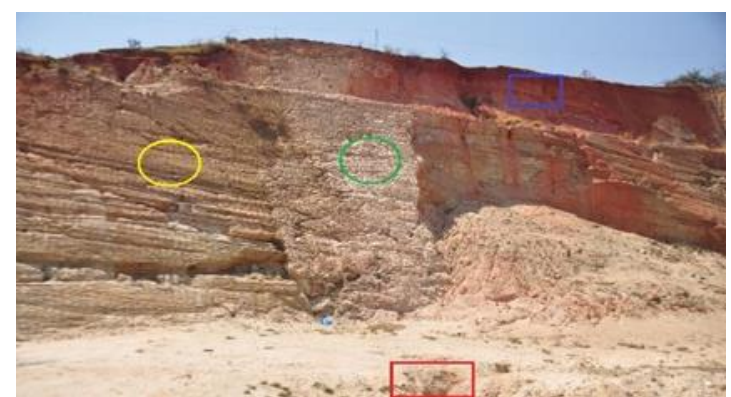

Figura 14: Local onde foi aberto o perfil A.5 - Antropossolo 5 (representado pelo retângulo vermelho). Apesar do perfil ter sido aberto no terço médio da antiga encosta, nessa imagem consegue-se visualizar a riqueza litológica da área onde a saibreira foi instalada. Identificou-se a presença de estrutura gnáissica intacta (representada pelo círculo amarelo) e ao lado estrutura metamorfizada (representado pelo círculo verde). Ainda é possível visualizar no canto superior o desenvolvimento pedogenético (representado pelo retângulo azul) e abaixo, a presença de saprófito.

Fonte: Autores (2019).

Foi classificado como mobílico, para subordem, devido à apresentar volume de material misturado como saprófitos, grãos de rochas e minerais sobre o solo que foi decapitado. Para grande grupo, foi classificado como inêquico, pois as camadas não seguem as disposições encontradas nos horizontes originais. Para subgrupo, foi caracterizado como Tb eutrófico, pois apresenta argila de baixa atividade, em campo não foram registradas altas pegajosidades, e V\% médio é superior a 50\% (Tabela X). 
A camada superficial (A.5.1) do perfil apresentou os maiores valores de $\mathrm{V} \%$ e $\mathrm{pH}$ de todas as camadas superficiais analisadas, $86,6 \%$ e 6,15 , respectivamente.

Tabela X: Resultados das análises químicas do perfil A.5 - Antropossolo 5.

\begin{tabular}{|c|c|c|c|c|c|c|c|c|c|}
\hline \multirow{2}{*}{$\begin{array}{l}\text { Perfil } \\
\text { A.5 }\end{array}$} & \multirow{2}{*}{$\begin{array}{l}\text { Horizonte } \\
\quad(\mathbf{c m})\end{array}$} & \multirow{2}{*}{ pH H2O } & $\mathbf{P}$ & K & $\mathrm{Ca}$ & Mg & $\mathrm{H}+\mathrm{Al}$ & SB & $\mathbf{t}$ \\
\hline & & & \multicolumn{2}{|c|}{-----mg/dm³----- } & \multicolumn{5}{|c|}{ - } \\
\hline \multirow{8}{*}{ 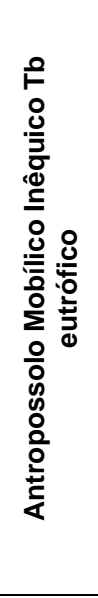 } & A.5.1 (0 - 20) & 6,15 & 23,60 & 27,00 & 3,13 & 1,32 & 0,70 & 4,52 & 4,52 \\
\hline & $\begin{array}{l}\text { A.5.2(20 - } \\
40)\end{array}$ & 6,16 & 10,30 & 27,00 & 3,26 & 1,27 & 0,80 & 4,60 & 4,80 \\
\hline & $\begin{array}{l}\text { A.5.3 }(40- \\
70)\end{array}$ & 6,27 & 18,00 & 21,00 & 2,45 & 1,21 & 0,70 & 3,71 & 4,01 \\
\hline & $\begin{array}{l}\text { A.5.4 (40 - } \\
100)\end{array}$ & 6,14 & 2,20 & 21,00 & 0,98 & 1,23 & 1,60 & 2,26 & 3,25 \\
\hline & Média & 6,18 & 13,53 & 24,00 & 2,46 & 1,26 & 0,95 & 3,77 & 4,15 \\
\hline & $\begin{array}{l}\text { Desvio } \\
\text { Padrão }\end{array}$ & 0,05 & 8,07 & 3,00 & 0,91 & 0,04 & 0,38 & 0,94 & 0,59 \\
\hline & Variância & 0,00 & 65,05 & 9,00 & 0,82 & 0,00 & 0,14 & 0,88 & 0,35 \\
\hline & $\begin{array}{l}\text { Coeficiente } \\
\text { de Variação }\end{array}$ & 0,85 & 59,63 & 12,50 & 36,88 & 3,34 & 39,74 & 24,92 & 14,22 \\
\hline \multirow{2}{*}{$\begin{array}{l}\text { Perfil } \\
\text { A.5 }\end{array}$} & \multirow{2}{*}{$\begin{array}{l}\text { Horizonte } \\
\quad(\mathrm{cm})\end{array}$} & $\mathbf{T}$ & V & $\mathbf{m}$ & P-rem & $\mathrm{Zn}$ & $\mathrm{Fe}$ & Mn & $\mathrm{Cu}$ \\
\hline & & $\begin{array}{c}\mathrm{cmolc} \\
/ \mathrm{dm}^{3}\end{array}$ & \multicolumn{2}{|c|}{-------\%------- } & $\mathrm{mg} / \mathrm{L}$ & \multicolumn{4}{|c|}{ 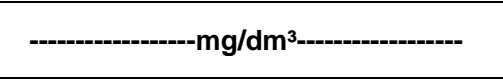 } \\
\hline \multirow{8}{*}{ 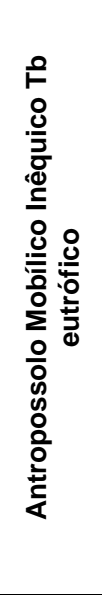 } & A.5.1 (0 - 20) & 5,22 & 86,60 & 0,00 & 54,60 & 0,56 & 13,10 & 8,10 & 0,27 \\
\hline & $\begin{array}{l}\text { A.5.2 }(20- \\
40)\end{array}$ & 5,40 & 85,20 & 4,20 & 54,00 & 0,57 & 10,70 & 5,80 & 0,28 \\
\hline & $\begin{array}{l}\text { A.5.3 }(40- \\
70)\end{array}$ & 4,41 & 84,10 & 7,50 & 55,70 & 1,02 & 14,20 & 6,10 & 0,23 \\
\hline & $\begin{array}{l}\text { A.5.4 (40 - } \\
100)\end{array}$ & 3,86 & 58,50 & 30,50 & 45,10 & 0,66 & 16,70 & 4,40 & 0,25 \\
\hline & Média & 4,72 & 78,60 & 10,55 & 52,35 & 0,70 & 13,68 & 6,10 & 0,26 \\
\hline & $\begin{array}{l}\text { Desvio } \\
\text { Padrão }\end{array}$ & 0,62 & 11,64 & 11,82 & 4,23 & 0,19 & 2,16 & 1,32 & 0,02 \\
\hline & Variância & 0,35 & 0,39 & 135,46 & 139,73 & 0,04 & 4,65 & 1,75 & 0,00 \\
\hline & $\begin{array}{l}\text { Coeficiente } \\
\text { de Variação }\end{array}$ & 14,22 & 13,17 & 14,81 & 112,05 & 26,68 & 15,77 & 21,66 & 7,46 \\
\hline
\end{tabular}

Fonte: Autores (2020).

Os valores de $\mathrm{pH}$, tiveram a média 6,18 , com baixos valores de desvio padrão e coeficiente de variação 0,052 e 0,85\%, respectivamente. Devido ao pH pouco ácido esse perfil apresentou os menores valores de $\mathrm{Zn}\left(0,56 \mathrm{mg} / \mathrm{dm}^{3}\right)$, Fe $\left(10,70 \mathrm{mg} / \mathrm{dm}^{3}\right)$, $\mathrm{Mn}\left(4,40 \mathrm{mg} / \mathrm{dm}^{3}\right)$ e $\mathrm{Cu}\left(0,23 \mathrm{mg} / \mathrm{dm}^{3}\right)$ de todas as análises. Além do mais, esse perfil apresentou o maior valor para a média do P-rem. As camadas 1, 2 e 3 apresentaram os maiores valores de P-rem, indicando a presença de um material com baixa retenção de $P$. 
É importante destacar que na camada superficial não foram detectados valores para a saturação por alumínio, pH em torno de 6,15. O horizonte A.5.4 serve como registro do solo natural que ali existia, sua análise química mostrou discordância nos valores de $\mathrm{P}$ e $\mathrm{Ca}$ apesar do $\mathrm{pH}$ não ser discordante das camadas superiores. $\mathrm{O}$ destaque fica para o menor valor de V\% (58,5\%) e o maior valor de $\mathrm{m} \%(30,5 \%)$ do perfil, indicando que o horizonte guarda características de um solo natural anterior, além da diminuição do P-rem. A classificação textural do perfil variou de Areia Franca a FrancoArenosa (Tabela XI).

Tabela XI: Resultados das análises físicas do perfil A.5 - Antropossolo 5.

\begin{tabular}{|c|c|c|c|c|c|c|}
\hline \multirow{2}{*}{ Perfil A.5 } & \multirow{2}{*}{ Horizonte $(\mathrm{cm})$} & Areia Grossa & Areia Fina & Silte & Argila & \multirow{2}{*}{$\begin{array}{c}\text { Classificação } \\
\text { Textural }\end{array}$} \\
\hline & & & -----kg/l & --------. & & \\
\hline \multirow{4}{*}{ 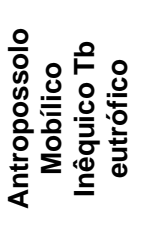 } & A.5.1 $(0-20)$ & 0,663 & 0,185 & 0,086 & 0,065 & Areia Franca \\
\hline & A.5.2 (20 - 40) & 0,616 & 0,174 & 0,127 & 0,083 & Areia Franca \\
\hline & A.5.3 $(40-70)$ & 0,633 & 0,215 & 0,076 & 0,076 & Areia Franca \\
\hline & A.5.4 (40 - 100) & 0,540 & 0,220 & 0,139 & 0,101 & Franco-Arenosa \\
\hline
\end{tabular}

Fonte: Autores (2020).

Esse perfil foi aberto em um local que demonstra a riqueza litológica da área e os principais processos erosivos que atuam na saibreira. A deposição desordenada e os materiais não estruturados combinam para que a erosão na área seja muito intensa, os processos de ravinamento, de transporte e deposição de material são bem nítidos.

\section{Conclusões}

Os cincos perfis de Antropossolos, classificados e descritos nesse artigo são reflexos de administrações e controles sobre a exploração dos recursos minerais em diversas escalas, onde o planejamento do uso da terra e seus impactos diretos e indiretos que podem levar a degradação de áreas, não são considerados e o principal benefício é, apenas, o econômico. A fiscalização mais incisiva poderia garantir e destinar os locais corretos para a deposição dos materiais retirados da saibreira, bem como definindo os modelos de exploração e recuperação para a área.

Algumas atividades minerais, em diferentes escalas, comumente, ocorrem à margem da lei. A saibreira de Santa Maria é uma área embargada, abandonada e não recuperada, portanto, é um problema para a região, em diferentes escalas. A participação da comunidade do distrito de Santa Maria, nas discussões/ações que envolvem a recuperação desta área, deve ser uma preocupação do poder público local, definindo a recuperação e, se for o caso, a reutilização da área.

Os perfis analisados mostram também, como a natureza é alterada pela atividade antrópica. A não preocupação ambiental pela mineração de saibro mostra como os impactos são sentidos em diversas partes. Por isso o assoreamento do Córrego Santa Maria e os depósitos aluviais foram destacados. 
As atividades antrópicas em diversas escalas produzem novos ambientes. Os estudos recentes sobre o Antropoceno, a proposta de Curcio et al. (2004) e o Sistema Brasileiro de Classificação de Solos - SiBCS (EMBRAPA, 2018) não apresentam conciliações quando se referem ao agente antrópico, mas as metodologias de análises são parecidas e essa dificuldade de linguagem única dificulta a classificação. É necessário a definição de um sistema único de classificação, que considere a evolução dos ambientes antrópicos e como esse agente formador modifica os lugares. Compreender sua espacialização, classificação e os diferentes resíduos depositados, pode gerar informações para seu planejamento e gestão, em diferentes escalas espaço-temporais.

Os avanços tecnológicos permitiram que a produção de informação, assim como, a evolução das técnicas de exploração de recursos minerais, fosse muito rápida. Nesse contexto, identificou-se que a antropogênese ocorreu em uma velocidade muito grande. A conciliação entre tecnologia e estudos sobre Antropossolos devem seguir em conjunto, para facilitar a identificação, a classificação e o mapeamento desses novos solos que possuem características únicas e locais, mas que impactam lugares a quilômetros de distância.

\section{Bibliografia}

Ab'Saber. A. N. (2003). Os Domínios da Natureza no Brasil: Potencialidades Paisagísticas. 7. ed. São Paulo: Ateliê Editorial. 158 p.

Brollo, M. J., Ferreira, C. J., Fernandes Da Silva, P. C., Tominaga, L. K., Vedovello, R., Guedes, A. C. M., Lopes, E. A., Oliveira, A. R., Ummus, M. E., Cripps, J. C. (2005). Caracterização das áreas degradadas por mineração de saibro em Ubatuba: condicionantes para a sua recuperação ambiental. In: ABGE, Congresso Brasileiro de Geologia de Engenharia e Ambiental, 11, Florianópolis, Anais.

CPRM, UFMG, BRASIL. (2006). Mapa Geológico. Folha VIÇOSA - SE-23-X-B-V. Disponível em 04/04/2020 em: http://rigeo.cprm.gov.br/jspui/bitstream/doc/17798/1/vicosa.pdf

Curcio, G. R., Lima, V. C., Giarola, N. F. B. (2004). Antropossolos: Proposta de Ordem (1 aproximação). Colombo, EMBRAPA Florestas, 49p.

EMBRAPA (2017). Centro Nacional de Pesquisa de Solos. Manual de Métodos de Análise de Solo. 3. ed. rev. e ampl. Rio de Janeiro, 577p.

EMBRAPA (2018). Sistema Brasileiro de Classificação de Solos. 5. ed. rev. ampl. Brasília, DF: EMBRAPA, 3560.

Guerra, A. T., Guerra, A. J. T. (2008). Novo Dicionário Geológico-Geomorfológico. 6ª ed. Rio de Janeiro: Bertrand, $652 \mathrm{p}$.

Minas Gerais (Estado). Lei № 21.972, de 21 de janeiro de 2016. Dispõe sobre o Sistema Estadual de Meio Ambiente e Recursos Hídricos - Sisema. Disponível em 04/04/2020 em: http://www.siam.mg.gov.br/sla/download.pdf?idNorma=40095

Oliveira, A. M. S., Brannstrom, C., Nolasco, M. C., Peloggia, A. U. G., Peixoto, M. N. O., Coltrinari, L. (2005) Tecnógeno: Registros da ação geológica do homem. In: 
QUATERNÁRIO do Brasil. Ribeirão Preto: Holos, cap. 17, p. 363-378. Disponível em 03/04/2020 em: http://www.abequa.org.br/livro.php

Peloggia, A. U., Oliveira, A. M. S. (2005). Tecnógeno: Um novo campo de estudos das Geociências. X Congresso da Associação Brasileira de Estudos do Quaternário (ABEQUA, 10), $4 p$.

Santos, R. D., Santos, H. G., Ker, J. C., Anjos, L. H. C., Shimizu, S. H. (2015). Manual de descrição e coleta de solo no campo. 7 ed. Sociedade Brasileira de Ciência do Solo, Viçosa, $102 \mathrm{p}$.

Novais, R. F., Alvarez V. V. H., Barros, N. F., Fontes, R. L. F., Cantarutti, R. B., Neves, J. C. L. (2007) Fertilidade do Solo. $1^{\underline{a}}$ ed. Sociedade Brasileira de Ciência do Solo, Viçosa. $1017 p$.

Sousa, L. F. C. (2019). Mapeamento de áreas de fragilidade ambiental no município de Visconde do Rio Branco. Monografia de Graduação. Bacharelado em Geografia, Universidade Federal de Viçosa, 50p.

Tarolli, P., Sofia, G. (2016). Human topographic signatures and derived geomorphic processes across landscapes. Geomorphology, 255,140-161.

Teixeira R. C. (2015). Antropossolo em Guarapari (ES): A Geografia dos Solos Antrópicos. Monografia de Graduação. Bacharelado em Geografia, Universidade Federal de Viçosa, $46 \mathrm{p}$.

Ter-Stepanian, G. (1988). Beginning of the Technogene. Bulletin of the International Association of Enginnering Geology, 38, 33-142.

Universidade Federal de Viçosa; Fundação Centro Tecnológico de Minas Gerais; Universidade Federal de Lavras; Fundação Estadual do Meio Ambiente. Mapa de solos do Estado de Minas Gerais. Belo Horizonte, Fundação Estadual do Meio Ambiente, (2010). Disponível em 04/04/2020 em: http://www.feam.br/noticias/1/949-mapas-de-solo-doestado-de-minas-gerais

Visconde do Rio Branco (2013). Prefeitura Municipal de Visconde do Rio Branco, MG. Plano Municipal de Saneamento Básico de Visconde do Rio Branco. Disponível em 26/04/2020 em: http://www.viscondedoriobranco.mg.gov.br/wp-content/uploads/2017/06/LEl-COMP_59-2016.pdf

Visconde do Rio Branco. (2020). A história. Disponível em 14/04/2020 em: https://www.viscondedoriobranco.mg.gov.br/historia/

Artigo recebido em / Received on: 15/02/2021

Artigo aceite para publicação em / Accepted for publication on: 30/12/2021 
Krause, Faria, Teixeira e Costa / Physis Terrae, Vol. 3, no1-2, 2021, 37-61

Página intencionalmente deixada em branco 